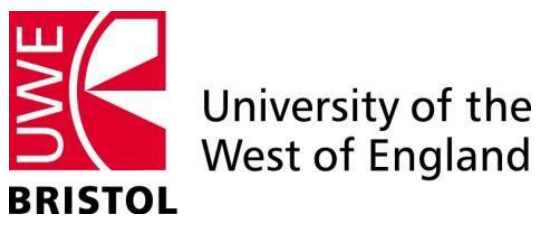

Faculty of Business and Law

\title{
Debt cycles, instability and fiscal rules: a Godley-Minsky model
}

\author{
Yannis Dafermos
}

\author{
Department of Accounting, Economics and Finance, \\ University of the West of England, Bristol, UK \\ Yannis.Dafermos@uwe.ac.uk
}

Economics Working Paper Series

1509 


\title{
Debt cycles, instability and fiscal rules: a Godley-Minsky model
}

\author{
Yannis Dafermos* \\ ${ }^{*}$ Department of Accounting, Economics and Finance, University of the West of England, \\ Bristol, UK, e-mail:Yannis.Dafermos@uwe.ac.uke
}

\begin{abstract}
Wynne Godley and Hyman Minsky were two macroeconomists who 'saw the crisis coming'. This paper develops a simple macrodynamic model that synthesises some key perspectives of their analytical frameworks. The model incorporates Godley's financial balances approach and postulates that private sector's propensity to spend is driven by a stock-flow norm (the target net private debt-to-income ratio) that changes endogenously via a Minsky mechanism. It also includes two fiscal rules: a Maastricht-type fiscal rule, according to which the fiscal authorities adjust the government expenditures based on a target net government debt ratio; and a Godley-Minsky fiscal rule, which links government expenditures with private indebtedness following a counter-cyclical logic. The analysis shows that (i) the interaction between the propensity to spend and net private indebtedness can generate cycles and instability; (ii) instability is more likely when the propensity to spend responds strongly to deviations from the stock-flow norm and when the expectations that determine the stock-flow norm are highly sensitive to the economic cycle; (iii) the Maastricht-type fiscal rule is destabilising while the Godley-Minsky fiscal rule is stabilising; and (iv) the paradox of debt can apply both to the private sector and to the government sector.
\end{abstract}

Keywords: Godley, Minsky, debt cycles, instability, fiscal rules

JEL Classification: E10; E20; E32; E62

\section{September 2015}

\footnotetext{
Acknowledgements: A previous version of this paper was presented at the Cambridge Keynes Seminar of the Post-Keynesian Economics Study Group in May 2014. I am grateful to Marco Passarella and Graham Gudgin for valuable comments. The paper has also benefited from comments and suggestions by Giorgos Galanis, Annina Kaltenbrunner, Andrew Mearman, Jo Michell, Maria Nikolaidi, Christos Papatheodorou, Engelbert Stockhammer and Rafael Wildauer. Any errors are mine.
} 


\section{Debt cycles, instability and fiscal rules: a Godley-Minsky model}

\section{Introduction}

Wynne Godley and Hyman Minsky were two macroeconomists who 'saw the crisis coming.'. In 1999 Godley published his well-known article on the 'seven unsustainable processes' in the US economy (Godley, 1999). In this article he argued that the rising indebtedness of the US private sector was unsustainable and, therefore, private expenditures could not be considered as a source of steady growth in the medium run. $\mathrm{He}$ also pointed to the unsustainability of the rising US net foreign indebtedness. Using a stock-flow consistent analytical framework, Godley argued that without a change in fiscal policy stance or an important rise in net exports, the US economy was doomed to witness a severe recession and a sharp rise in unemployment. These warnings were repeated in his publications as a head of the Levy Economics Institute's macro-modelling team (see, e.g. Godley, 2003, 2005; Godley et al., 2005). The 2007-9 crisis verified Godley's fears: the US economy contracted sharply and the unemployment rate increased substantially. ${ }^{2}$

Minsky $(1975,1982,2008)$ developed a theory that explains how indebtedness can increase in periods of tranquillity as a result of endogenous forces that reduce the desired margins of safety of economic units. This gradual reduction in the desired margins of safety was considered by Minsky as the reason behind the increasing financial fragility that accompanies economic expansion and periods of stability. According to his financial instability hypothesis, the increasing fragility makes the macro systems more prone to shocks that reduce the ability of borrowers to repay their debt. These shocks can lead to severe economic recessions. The processes described in Minsky's analysis are broadly in line with the pre-crisis developments in the US and other advanced economies that ultimately led to the Great Recession.

The emphasis that Godley and Minsky placed on financial relationships as sources of cycles and instability enabled them to provide some very important insights into the dynamics of modern macroeconomies. However, they did so from quite different angles. Godley concentrated more on the macroeconomic relationships between the private, the government and the foreign sector and postulated that in the medium to long run the fluctuations in financial balances and growth are driven by some exogenous stock-flow norms. Minsky, on the other hand, focused more on the relationships within the private sector (primarily on the financial relationships between firms and banks) and explained the macroeconomic fluctuations by considering endogenous changes in norms and valuations of risk.

Although it is widely held that Godley's and Minsky's perspectives are both important for the explanation of macroeconomic dynamics, there is still a lack of a formal

\footnotetext{
${ }^{1}$ See, for example, Whalen (2008), Wolf (2008), Bezemer (2010) and Wray (2011, 2012).

2 According to Godley et al. (2007) and Zezza (2009), the slowdown of economic growth in 2001-2 was a first sign of the unsustainable processes in the US economy. However, a severe recession was then prevented due to accommodative fiscal and monetary policies.
} 
framework that synthesises them. On the one hand, there is a large literature on formal Minskyan models that capture various dynamics related to Minsky's financial instability hypothesis. Recent contributions to this literature include Ryoo (2010, 2013a), Chiarella and Di Guilmi (2011), Eggertsson and Krugman (2012), Passarella (2012), Sordi and Vercelli (2012), Keen (2013), Nikolaidi (2014) and Bhattacharya et al. (2015). However, none of these models include explicitly insights from Godley's projection analyses. On the other hand, there are some theoretical stock-flow consistent models that utilise aspects of Godley's projection approach, but make no explicit links to Minskyan dynamics (e.g. Godley and Lavoie, 2007; Martin, 2008; Leite, 2015).

The purpose of this paper is to develop a simple macrodynamic model that makes a Godley-Minsky synthesis. The model concentrates on certain aspects of Godley's and Minsky's approaches that are deemed more important for a simplified explanation of debt cycles and instability in a national macroeconomy. The key features of the model and the principal results of the analysis are the following.

First, as in Godley's projection analyses, the model economy consists of three sectors: the private sector, the government sector and the foreign sector. This permits an explicit consideration of Godley's financial balances approach that explains the interlinkages between these sectors and the resulting effects on debt accumulation and growth. Remarkably, Godley's financial balances approach is broadly in line with Kalecki's profit equation that was used by Minsky.

Second, drawing on Godley, the private sector's propensity to spend is driven by a stock-flow norm (the target net debt-to-income ratio). It is shown that, under certain conditions, the interaction between the propensity to spend and net private indebtedness generates cycles and instability. Instability is more likely when the propensity to spend responds strongly to deviations from the stock-flow norm. A paradox of debt result arises: the more the private sector and its lenders attempt to put net private indebtedness under control, by adjusting private expenditures, the more the net private debt ratio destabilises.

Third, following Minsky, it is assumed that the stock-flow norm varies endogenously as a result of changes in the expectations and the conventions of borrowers and lenders during the economic cycle. It is shown that this endogeneity can give rise to GodleyMinsky debt cycles and it is a source of instability. Instability is more likely when the stock-flow norm is highly sensitive to the economic cycle.

Fourth, two different fiscal rules are introduced: a Maastricht-type fiscal rule, according to which the fiscal authorities adjust the government expenditures based on a target net government debt ratio; and a Godley-Minsky fiscal rule, which links government expenditures with private indebtedness following a counter-cyclical logic. Simulation analysis illustrates that the Maastricht-type fiscal rule is destabilising while the GodleyMinsky fiscal rule is stabilising. Apart from supporting the view that counter-cyclical fiscal policy has positive effects on the stabilisation of output, this result suggests that countercyclical fiscal policy is also conducive to the stabilisation of government indebtedness. Moreover, it is shown that the paradox of debt can apply to the government sector: the more the fiscal authorities attempt to target a specific government debt ratio, by adjusting the government expenditures, the more this ratio destabilises.

The paper proceeds as follows. Section 2 lays out the structure of the model. Section 3 explores the interaction between private sector's propensity to spend and net private 
indebtedness when the target net private debt-to-income ratio and government expenditures are exogenous. Section 4 endogenises the target net private debt-to-income ratio and studies how Godley-Minsky cycles can arise. It also examines the implications of this endogeneity for instability. Section 5 introduces fiscal rules and analyses their (de)stabilising effects. Section 6 summarises and concludes.

\section{Structure of the model}

Table 1 portrays the transactions matrix of our three-sector economy. National accounting implies:

$Y=C+I+G+X-M$

$Y_{P}=Y-T-r D_{P}$

$S=Y_{P}-C$

$\dot{D}_{P}=-B_{P}=P-Y_{P}$

$\dot{D}_{G}=-B_{G}=G-T+r D_{G}$

$\dot{D}_{F}=-B_{F}=X-M-r\left(D_{P}+D_{G}\right)$

$D_{P}+D_{G}+D_{F}=0$

$\dot{D}_{P}+\dot{D}_{G}+\dot{D}_{F}=-\left(B_{P}+B_{G}+B_{F}\right)=0$

where $Y$ is the output of the economy, $C$ is consumption, $I$ is domestic investment, $G$ denotes primary government expenditures, $X$ denotes exports, $M$ denotes imports, $Y_{P}$ is the disposable income of the private sector, $S$ is private sector's saving, $P$ denotes the total private expenditures $(C+I), D_{P}$ is the net private debt, $B_{P}$ is the balance of the private sector, $B_{G}$ is the balance of the government sector, $T$ denotes taxes, $r$ is the interest rate, $D_{G}$ is the net government debt, $B_{F}$ is the balance of the foreign sector and $D_{F}$ is the net foreign debt. The net debt of each sector is equal to its financial liabilities minus its financial assets. A sector is a net debtor when its net debt is positive and a net creditor when its net debt is negative. A dot over a variable $x$ is used to denote time derivative $(\dot{x}=d x / d t)$.

For simplicity, the following assumptions have been made: the interest rate is exogenously determined by the monetary authorities and is the same for both the private and the government net debt; ${ }^{3}$ the primary government expenditures refer only to the purchase of goods produced by the private sector; the price level is set equal to unity; there are no changes in asset prices and exchange rates that could affect the value of assets and liabilities (and, thus, the value of net debt).

3 The assumption that the interest rate is exogenous, and thus independent of the level of (private and government) indebtedness, seems quite restrictive. However, this assumption has been adopted because one of the purposes of this model is to show that indebtedness can be a source of cycles and instability even when it has no direct impact on the interest rates. Note, though, that the adverse effects that high indebtedness can have on the new debt inflow (by causing a rise in the interest rates) are implicitly incorporated in Eqs. (16) and (18a) below. 
Table 1. Transactions matrix.

\begin{tabular}{lccccc}
\hline & \multicolumn{2}{c}{ Private sector } & \multirow{2}{*}{ Government sector } & Foreign sector & \multirow{2}{*}{ Total } \\
\cline { 2 - 3 } & Current & Capital & & $-G$ & 0 \\
Government expenditures & $+G$ & & $+T$ & 0 \\
Taxes & $-T$ & & $-X$ & 0 \\
Exports & $+X$ & & $+M$ & 0 \\
Imports & $-M$ & & & 0 \\
Domestic investment & $+I$ & $-I$ & $-S$ & & 0 \\
Private sector's saving & $-S$ & $+S$ & $-r D_{F}$ & 0 \\
Interest & $-r D_{P}$ & & $+\dot{D}_{G}$ & $+\dot{D}_{F}$ & 0 \\
Change in net debt & & $+\dot{D}_{P}$ & 0 & 0 & 0 \\
\hline Total & 0 & 0 & & & 0 \\
\hline
\end{tabular}

Particular attention should be paid to identity (8). This identity reflects Godley's financial balances approach. ${ }^{4}$ It states that the sum of the balances of the three sectors of the economy is equal to zero. This identity has been widely used by Godley himself and other economists to analyse the macroeconomic developments in various countries (see e.g. Godley, 1995, 1999, 2003, 2005; Godley et al., 2007; Zezza, 2009; Sawyer, 2011; Brecht et al., 2012; Wolf, 2012). The important implication of this identity is that the balance of one sector cannot improve without a deterioration in the balance of at least one of the other two sectors. Therefore, if, for example, the government sector desires to decrease its deficit to a specific level then the private sector and/or the foreign sector should be willing to accept a deterioration of their balances in an accurately offsetting manner. Otherwise, the intended decline in deficit cannot be attained. Moreover, since most components of the financial balances are also components of the aggregate demand, any attempt of the sectors to improve their balances may lead to lower output if the other sectors do not desire to experience lower balances.

A distinguishing feature of the financial balances approach is the consolidation of households, firms and banks into one single private sector. This implies that in our model the transactions between households, firms and banks are not taken explicitly into consideration. Moreover, the assets and the liabilities of the private subsectors that are counterparts of the assets and liabilities of other private subsectors are netted out in the estimation of the net private debt. The net private debt refers, therefore, solely to the net liabilities of the private sector that are net assets of the government and the foreign sector. Although this consolidation is a great simplification with various limitations (see Dos Santos and Macedo e Silva, 2010 and Martin, 2012 for a discussion), it has proved quite useful in Godley's projections and other empirical analyses that focus on the interaction between private sector's behaviour, fiscal policy and foreign balance. Moreover, it serves the purposes of our simple skeleton that intends to capture the dynamics of a national macroeconomy by using a high-level aggregation.

We have that:

${ }^{4}$ For an analysis of this approach see Godley and Cripps (1983), Godley (1995), Zezza (2009), Dos Santos and Macedo e Silva (2010), Kregel (2011), Brecht et al. (2012) and Wray (2012). 
$p=\frac{P}{Y-T}$

$g=\frac{G}{Y}$

$d_{P}=\frac{D_{P}}{Y-T}$

$d_{G}=\frac{D_{G}}{Y}$

where $p$ is private sector's propensity spend out of its income, ${ }^{5} g$ is the government expenditures-to-output ratio, $d_{P}$ is the net private debt-to-income ratio and $d_{G}$ is the net government debt-to-output ratio.

Eqs. (13) and (14) imply that the taxes and the imports are proportional to the output of the economy $(\tau, m>0)$.

$$
\begin{aligned}
& T=\tau Y \\
& M=m Y
\end{aligned}
$$

Eq. (15) shows that, for simplicity, the exports grow at an exogenously given rate, $g_{X}$. This rate relies on factors such as the economy's structural competiveness and the income of the foreign sector, which are taken as given.

$\dot{X}=g_{X} X$

Godley argued that the private sector targets in the long run a specific stock of net financial assets as a proportion of its disposable income (a stock-flow norm). He also postulated a formula which states that the balance of the private sector adjusts in order for this desired stock to be attained (see Godley and Cripps, 1983; Godley, 1999; Godley and Lavoie, 2007). ${ }^{6}$ In our model this idea is captured by the following equation:

$\dot{p}=\lambda\left(d_{P}^{T}-d_{P}\right)$

In Eq. (16) $d_{P}^{T}$ expresses the target net private debt-to-income ratio. It is deemed that this target in not only set by the private sector itself. It is also set by the government and, most importantly, by the foreign sector that are potentially lenders of the private sector. For instance, it may capture the willingness of foreign investors to lend to the private sector of a national economy (households, firms or banks). Therefore, this target is affected by the decisions of both borrowers and lenders. ${ }^{7}$

\footnotetext{
${ }^{5}$ For simplicity, in Eqs. (9) and (11) we use the private sector's income after taxes, but before the interest payments.

${ }^{6}$ See also Martin (2012) and Shaikh (2012).

7 Recall that the private sector can be either a net debtor (when the net private debt is positive) or a net creditor (when the net private debt is negative).
} 
Formula (16) implies that the private sector's propensity to spend increases (decreases) when the actual net debt ratio is lower (higher) than the targeted one (i.e. $\lambda>0)$. A change in the propensity to spend may express the decisions of both the private sector and its lenders. Importantly, although a change in the propensity to spend is the primary means through which the private sector can affect its net indebtedness, it may not have the desired outcomes. As will become clear below, the decision for spending affects the output of the economy and, therefore, has feedback effects on the net private debt-toincome ratio.

Eq. (16) can capture changes in private expenditures caused by capital inflows and capital outflows. For example, the inequality $d_{P}^{T}>d_{P}$ may reflect periods in which the net debt of the private sector is considered by foreign lenders as sufficiently small. In such periods the existence of a low perceived lender's risk induces higher capital inflows that lead to higher private expenditures relative to income. On the other hand, the inequality $d_{P}^{T}<d_{P}$ may capture periods of capital outflows in which the lender's risk is perceived to be high.

Interestingly, formula (16) shares some similarities with the recent macroeconomic analysis of Koo (2013) about what he calls a 'balance sheet recession'. In this analysis Koo makes a distinction between periods in which the private sector maximises profits ('Yang phases') and periods in which the private sector minimises its debt ('Yin phases'). In our model, the reduction in the private sector's propensity to spend when $d_{P}^{T}<d_{P}$ resembles a 'Yin phase' à la Koo. Similarities also exist between Eq. (16) and the formalisation in the model of Eggertsson and Krugman (2012) in which it is assumed that borrowers-lenders relationships are driven by a debt limit.

Although Godley postulated that the stock-flow norm is exogenous, it is clear that such an assumption can be considered satisfactory only as a first approximation. In reality, economic units' desired margins of safety, which determine the stock-flow norm, change endogenously during the economic cycle. Minsky (2008, pp. 193, 209) argued that during periods of expansion -when the outstanding debts are serviced without significant problems- the desired margins of safety of borrowers and lenders decline. This happens because the recent good performance of the economy and the favourable credit history induce economic units to accept financial structures that were previously assessed as risky. The opposite holds in periods in which the economic performance and credit history are not favourable. ${ }^{8}$ This endogenous responsiveness of the perceptions of risk to the economic fluctuations is in line with the empirical features of financial cycles (see Borio, 2013).

Although Minsky's arguments primarily refer to the behaviour of firms and banks, they can be applied to any borrower-lender relationship and, therefore, to the financial relationships between the private sector of a national economy and its lenders/borrowers (the government and the foreign sector). Therefore, drawing on the above-mentioned perspectives, we postulate the following specification:

$$
\dot{d}_{P}^{T}=\theta_{1}\left(g_{Y}-g_{Y 0}\right)+\theta_{2}\left(d_{P}^{B}-d_{P}^{T}\right)
$$

8 See also Kregel (1997), Tymoigne (2009), Vercelli (2011) and Lavoie (2014, p. 446). 
Eq. (17) states that when economic growth $\left(g_{Y}\right)$ is higher (lower) than a benchmark growth rate $\left(g_{Y 0}\right)$, the target net debt-to-income ratio of the private sector increases (decreases); note that $\theta_{1}>0 .{ }^{9}$ By endogenising the target net private debt-to-income ratio, Eq. (17) can be viewed as a Minskyan extension of Godley's exogenous stock-flow norm for the private sector. In Section 4 it will be shown that this endogeneity can increase the amplitude of the cycles and can be conducive to higher instability.

Although our model abstracts from asset price inflation, it should be pointed out that the postulated impact of economic growth on the target net debt-to-income ratio of the private sector is compatible with the role that asset prices play in Minskyan dynamics. ${ }^{10}$ Higher economic growth can induce households to take more risky positions by increasing the proportion of their assets that is held in the form of equities or by increasing their investment in the housing market. The resulting rise in asset prices can lead to a higher target debt ratio either directly (by improving the state of confidence) or indirectly (by affecting positively various economic variables, such as consumption, investment, the profitability of firms and the value of collateral). Therefore, although our model does not explicitly incorporate asset price inflation, Eq. (17) can implicitly capture the destabilising role of asset prices, which is important in Minsky's analyses.

However, economic growth is not the only driver of the target net debt ratio in our model. According to Eq. (17), this target is also partially attracted by a benchmark net debt ratio, $d_{P}^{B}$, which depends on deep economic, institutional and social factors (e.g. the degree of financialisation, the degree of openness of the domestic financial system, the prevailing consumption and investment norms, the society's perception of the role of debt, etc.); note that $\theta_{2}>0$. When $d_{P}^{B}>0$, the private sector has a net debtor benchmark position; when $d_{P}^{B}<0$, it has a net creditor benchmark position.

The benchmark net debt ratio is expected to change over a long-run horizon. For example, over the 1990s and the 2000s many advanced economies experienced a sustained reduction in the balance of their private sector (see, for example, Tymoigne and Wray, 2014, pp. 107-112). It is very likely that this reduction partially reflected deep economic, institutional and social economic changes that took place over this period, such as financial deregulation, financial globalisation and the gradual prevalence of norms that were conducive to higher levels of consumption and debt. These fundamental changes probably moved the private sector in these countries towards a net debtor benchmark position.

Overall, according to Eq. (17), the target net debt-to-income ratio depends on (a) cyclical changes in economic growth and (b) deep long-run economic, institutional and social factors. Following the distinction that Palley (2011) has made between Minsky basic cycle and Minsky super cycle, it could be argued that the cyclical changes effects are related to the Minsky basic cycle, while the deep long-run factors have to do with the Minsky super cycle which has a longer time horizon. In this paper, $d_{P}^{B}$ is deemed constant

\footnotetext{
${ }^{9}$ For a similar formulation that focuses on the endogeneity of the desired margins of safety of firms and banks see Nikolaidi (2014).

${ }^{10}$ For recent Minskyan models that incorporate explicitly this role see Ryoo (2010, 2013a), Chiarella and Di Guilmi (2011) and Passarella (2012).
} 
and, therefore, emphasis is placed on the dynamics linked with the basic Minsky cycle. However, future extension of this model could allow $d_{P}^{B}$ to change endogenously permitting thereby the combination of the Minsky basic cycle with the Minsky super cycle. ${ }^{11}$

In our model the dynamic behaviour of $g$ is determined by fiscal rules. Fiscal rules have been widely adopted over the past two decades or so. These rules impose constraints on fiscal aggregates, such as government debt and deficit (see IMF, 2009; Schaechter et al., 2012; Chortareas, 2013). We first consider a simple Maastricht-type rule which states that government expenditures (relative to output) decline when the net government debt-tooutput ratio is higher than a specific target $\left(d_{G}^{T}\right)$. Formally, this rule is written as follows:

$\dot{g}=\mu\left(d_{G}^{T}-d_{G}\right)$

where $\mu>0$. Note that the essence of this rule would not change if the tax rate was used as a tool instead of the government expenditures.

We then consider an alternative fiscal rule that departs from the conventional approach since it places no limits on any specific fiscal aggregate. On the contrary, its rationale is that fiscal policy should stabilise the macroeconomy by increasing (decreasing) government expenditures when the private sector exerts contractionary (expansionary) pressures as a result of its attempts to reduce (increase) its indebtedness. Formally:

$\dot{g}=-\kappa\left(d_{P}^{T}-d_{P}\right)$

where $\kappa>0$.

Eq. (18b) is consistent with the perceptions of both Godley and Minsky who emphasised that the government should intervene to offset fluctuations in economic activity that stem from the inherently unstable behaviour of the private sector. ${ }^{12}$ We thus call Eq. (18b) a Godley-Minsky fiscal rule.

Combining Eqs. (1), (9), (10), (13) and (14), we get:

$Y=p Y(1-\tau)+g Y+X-m Y$

Solving the above equation for $Y$, yields:

$Y=\frac{X}{1+m-p(1-\tau)-g}$

11 For a Minsky model that formalises these two cycles in a single framework see Ryoo (2010). His model relies on a Harrodian perspective and concentrates on the interactions between households, firms and commercial banks.

12 For a fiscal rule that relies on a similar rationale see Nikolaidi (2014). Interestingly, the Godley-Minsky fiscal rule is in line with Koo's (2013) proposition that during 'Yin phases' fiscal expansion is necessary in order to avoid deep recessions. 
The denominator in Eq. (20) must be positive (i.e. $1+m-p(1-\tau)-g>0$ ) to ensure goods market stability.

Differentiating Eq. (20) with respect to time and dividing through by $Y$, gives the growth rate of the economy:

$$
\frac{\dot{Y}}{Y}=g_{Y}=g_{X}+\frac{\dot{p}(1-\tau)+\dot{g}}{1+m-p(1-\tau)-g}
$$

Using Eqs. (2), (4), (9), (11), (13) and (21), we get:

$$
\dot{d}_{P}=\frac{\dot{D}_{P}}{Y(1-\tau)}-d_{P} \frac{\dot{Y}}{Y}=p-1+\left(r-g_{Y}\right) d_{P}
$$

Employing Eqs. (5), (10), (12), (13) and (21), we get:

$$
\dot{d}_{G}=\frac{\dot{D}_{G}}{Y}-d_{G} \frac{\dot{Y}}{Y}=g-\tau+\left(r-g_{Y}\right) d_{G}
$$

Eqs. (22) and (23), in conjunction with (21), show that when the private and the government sector decide to spend less (relative to income) the impact on their net debtto-income ratios depends on whether they are net debtors or net creditors. When the net debt is positive, there are two counteracting effects. On the one hand, the decline in expenditures (i.e. in $p$ and $g$ ) tends to reduce the net debt-to-income ratios. We call this the 'spending effect'. On the other hand, such a decline reduces $g_{Y}$ which in turn places upward pressures on the positive net debt-to-income ratios by reducing their denominator. We call this the 'growth effect'. However, when the net debt is negative, these two effects are mutually reinforcing. The reason is that a lower $g_{Y}$ reduces the denominator in the negative net debt-to-income ratios making them more negative.

Combining Eqs. (4)-(6) and (9)-(14), we can write the balances of the three sectors as a proportion of output:

$$
\begin{aligned}
& b_{P}=\frac{B_{P}}{Y}=\left(1-p-r d_{P}\right)(1-\tau) \\
& b_{G}=\frac{B_{G}}{Y}=\tau-g-r d_{G} \\
& b_{F}=\frac{B_{F}}{Y}=m-\frac{X}{Y}+r\left[d_{P}(1-\tau)+d_{G}\right]
\end{aligned}
$$

Note that $b_{P}+b_{G}+b_{F}=0 .{ }^{13}$

Eqs. (16), (17), (18), (22) and (23) constitute a 5D dynamic system, which is reproduced below for convenience: ${ }^{14}$

13 This can be easily shown by substituting the ratio $X / Y$ from Eq. (20) into Eq. (26) 
$\dot{d}_{P}=p-1+\left(r-g_{Y}\right) d_{P}$

$\dot{p}=\lambda\left(d_{P}^{T}-d_{P}\right)$

$\dot{d}_{P}^{T}=\theta_{1}\left(g_{Y}-g_{Y 0}\right)+\theta_{2}\left(d_{P}^{B}-d_{P}^{T}\right)$

$\dot{d}_{G}=g-\tau+\left(r-g_{Y}\right) d_{G}$

$\dot{g}=\mu\left(d_{G}^{T}-d_{G}\right)$

$\dot{g}=-\kappa\left(d_{P}^{T}-d_{P}\right)$

The system has a unique steady state. The steady-state values (denoted by the subscript ${ }_{0}$ ) for the state variables of the system are:

$d_{P 0}=d_{P 0}^{T}=d_{P}^{B}$

$d_{G 0}=d_{G}^{T}$

$p_{0}=1+\left(g_{X}-r\right) d_{P}^{B}$

$g_{0}=\tau+\left(g_{X}-r\right) d_{G}^{T}$

Note that $d_{P}^{B}$ and $d_{G}^{T}$ are parameters. At the steady state we also have that:

$g_{Y o}=g_{X}$

$b_{P 0}=-g_{X} d_{P}^{B}(1-\tau)$

$b_{G 0}=-g_{X} d_{G}^{T}$

$b_{F 0}=g_{X}\left[d_{P}^{B}(1-\tau)+d_{G}^{T}\right]$

Prior to proceeding to the analysis of the dynamic macro system and its subsystems it is useful first to briefly examine the law of motion of private and government net indebtedness when economic growth is exogenous. This can be done by assuming that $p$, $g$ and $d_{P}^{T}$ are at their steady-state values, and thereby $\dot{p}=\dot{g}=0$. Eq. (20) suggest that in this case economic growth is equal to the growth rate of exports (i.e. $g_{Y}=g_{X}$ ).

Under these conditions, from Eqs. (22) and (23) we get:

$\partial \dot{d}_{P} / \partial d_{P}=r-g_{X}$

$\partial \dot{d}_{G} / \partial d_{G}=r-g_{X}$

Therefore, the net private debt-to-income ratio and the net government debt-tooutput ratio are stable when $g_{X}>r$. This implies that when economic activity is exogenous, the stability of the net debt ratios relies on the export performance of the economy and the stance of monetary policy. The lower the interest rate set by monetary

14 When Eq. (18b) is utilised instead of (18a), the whole macro system is indeed a 4D system since $d_{G}$ has no feedback effects on the other state variables. 
authorities and the higher the export growth of the national macroeconomy, the higher the likelihood that the debt ratios will stabilise.

In the dynamic analysis and the simulations that follow it will be assumed that $g_{X}>r$. This will allow us to confine our attention to the destabilising forces that stem from the Godleyan and Minskyan mechanisms described above. The parameter values used in the simulation exercises and their justification are reported in Appendix A. ${ }^{15}$

\section{The 2D subsystem: interaction between private sector's propensity to spend and net private indebtedness}

This section analyses the 2D subsystem consisting of Eqs. (16) and (22). Our aim is to examine the dynamic interaction between private sector's propensity to spend and net private indebtedness when the target net private debt-to-income ratio and government expenditures are exogenous. Hence, $g$ and $d_{P}^{T}$ are kept at their steady-state values (i.e. $g=g_{0}$ and $\left.d_{P}^{T}=d_{P}^{B}\right) ; d_{G}$ is not necessary to be kept at its steady-state value since it does not feed back into the law of motion of $d_{P}$ and $p$. The following proposition holds.

Proposition 1. Consider the system consisting of Eqs. (16) and (22).

(a) If $d_{P}^{B} \leq 0$, the steady state of the system is locally stable.

(b) If $d_{P}^{B}>0$, there exists a parameter value $\lambda^{*}>0$ that satisfies the following properties:

(i) the steady state of the system is locally stable for all $\lambda \in\left(0, \lambda^{*}\right)$.

(ii) the steady state of the system is locally unstable for all $\lambda \in\left(\lambda^{*},+\infty\right)$.

(iii) the system undergoes a Hopf bifurcation at $\lambda=\lambda^{*}$ (in other words, there exists a limit cycle around the steady state for some range of the parameter value $\lambda$ which is sufficiently close to $\left.\lambda^{*}\right)$.

Proof. See Appendix B.

Proposition 1 suggests that when the private sector has a net creditor benchmark position, Eq. (16) does not produce destabilising forces: the stabilising impact of a change in the propensity to spend is reinforced by the associated 'growth effect' (see Section 2). ${ }^{16}$ On the contrary, when the private sector has a net debtor benchmark position, the likelihood that the system is unstable is higher the higher is the responsiveness of the propensity to spend to the divergence between the actual and the target net private indebtedness. The rationale behind this result is straightforward: when the net private debt ratio is higher (lower) than the target one, any attempt of the private sector to reduce (increase) its indebtedness by reducing (raising) the propensity to spend has an adverse (favourable) impact on economic growth. For sufficiently high values of $\lambda$, this 'growth effect'

15 The MATLAB codes for the simulations of this paper draw on Nikolaidi (2014).

${ }^{16}$ Stability also arises in the marginal case in which the private sector is in a zero net debt benchmark position (i.e. $d_{P}^{B}=0$ ). 
dominates the 'spending effect' leading to instability. It is interesting to note that, as shown in Appendix B, $\lambda^{*}$ becomes higher when the interest rate declines or the growth rate of exports increases. This implies that adequate monetary and trade policy can, until some limit, prevent the destabilising forces that stem from the behaviour of the private sector

Figure 1 presents the limit cycle that is generated when $\lambda=\lambda^{*} \approx 0.0153$ and $d_{P}^{\mathrm{B}}>0$. Suppose that the economy is initially in phase I. Since $d_{P}<d_{P}^{T}$, the private sector increases its propensity to spend, producing higher than steady-state growth. Simultaneously, net private indebtedness declines because the propensity to spend is not high enough. Phase I can be interpreted as a phase of recovery. As the net private debt-to-income ratio declines, $p$ continues to increase and eventually the economy enters phase II in which the propensity to spend is high enough to generate a rise in indebtedness. In this phase the economy continues to exhibit a high growth which, however, is accompanied by higher fragility. At some point, $d_{P}$ becomes higher than $d_{P}^{T}$. At that point the indebtedness of the private sector is conceived to be extremely high from the borrowers' and/or lenders' perspective. This causes a reduction in private sector's propensity to spend. The economy enters a period of stagnation (phase III) where low growth coexists with rising net indebtedness. This rising indebtedness reduces further the private sector's propensity to spend. Indebtedness starts declining only when the propensity to spend is low enough to outweigh the adverse affects of low growth on the debt ratio. When this happens, the economy enters a new phase (phase IV) where economic growth remains low (since $d_{P}$ is still higher than $d_{P}^{T}$ ). However, declining indebtedness sets the stage for the recovery that occurs when $d_{P}$ falls short of $d_{P}^{T}$. When this happens, a new cycle begins.

The cycles depicted in Fig. 1 could be characterised as 'Godley cycles', since they stem from private sector's attempt to achieve an exogenous stock-flow norm by modifying its propensity to spend. These cycles are broadly in line with the empirical evidence provided by Koo (2013) according to which the saving behaviour of the private sector (motivated by the willingness to leverage or deleverage) was the principal driver of expansions and contractions in many advanced economies over the last decades. 
Fig. 1. Limit cycle in the $2 \mathrm{D}$ subsystem; private sector in a net debtor benchmark position

$$
\left(d_{P}^{B}>0\right) ; \lambda=\lambda^{*} \approx 0.0153 .
$$

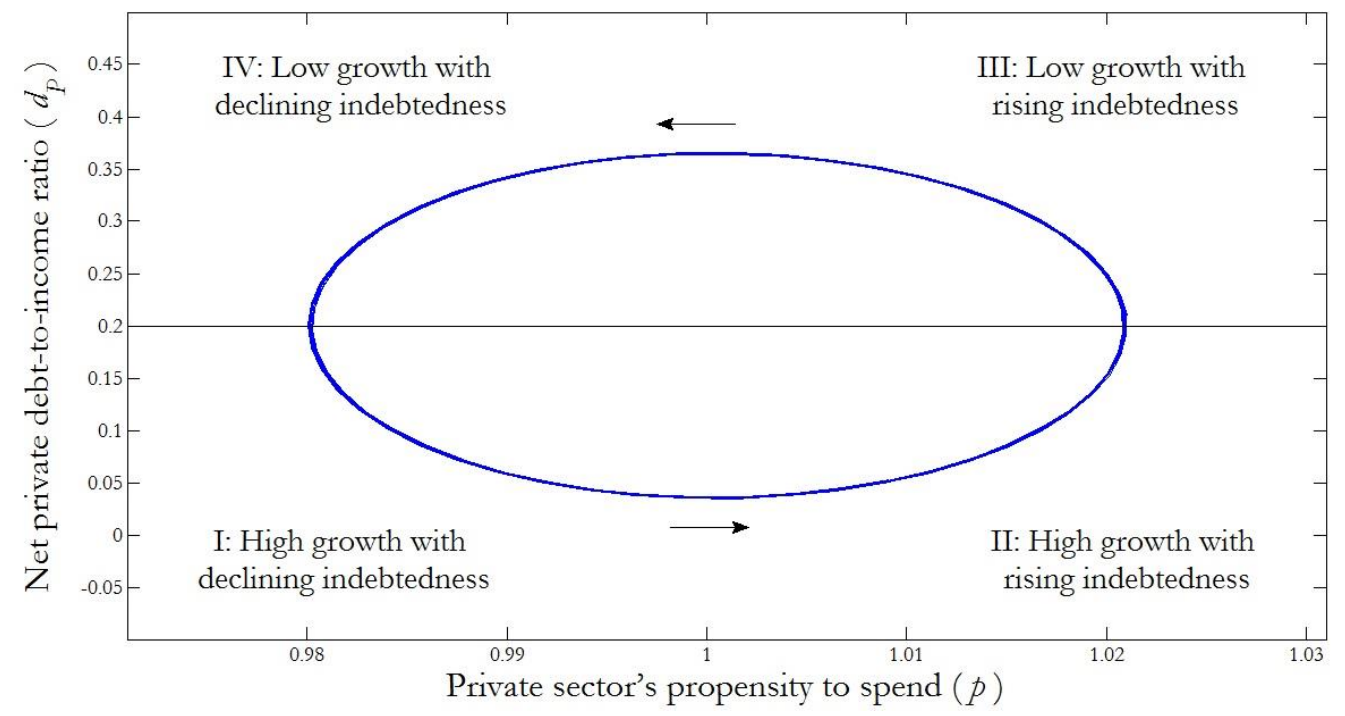

Fig. 2 illustrates that when $\lambda>\lambda^{*}$, the amplitude of the Godley cycles gradually increases and the economy becomes unstable. ${ }^{17}$ This happens because the propensity to spend responds strongly to deviations of the actual debt ratio from its target value. Therefore, the more the private sector and its lenders attempt to put net private indebtedness under control, by adjusting private expenditures, the more the private debt ratio destabilises. Arguably, this is a paradox of debt result. Although the adjustment of the propensity to spend seems to be a sensible behaviour for the control of private indebtedness, the resulting macroeconomic effects prevent the realisation of the desired indebtedness. ${ }^{18}$

${ }^{17}$ For a very wide range of parameter values above $\lambda^{*}$, the discriminant of the $2 \mathrm{D}$ subsystem (evaluated at the steady state) remains negative. Hence, the system exhibits oscillatory instability.

${ }^{18}$ For the paradox of debt in the case of firms see Steindl (1976), Lavoie (1995), Hein (2007), Passarella (2012) and Ryoo (2013b). 
Fig. 2. Dynamic adjustments of the $2 \mathrm{D}$ subsystem to a $5 \%$ positive shock in the net private debtto-income ratio; private sector in a net debtor benchmark position $\left(d_{P}^{B}>0\right)$; $\lambda=0.08>\lambda^{*} \approx 0.0153$.

(a) Net private debt-to-income ratio $\left(d_{P}\right)$

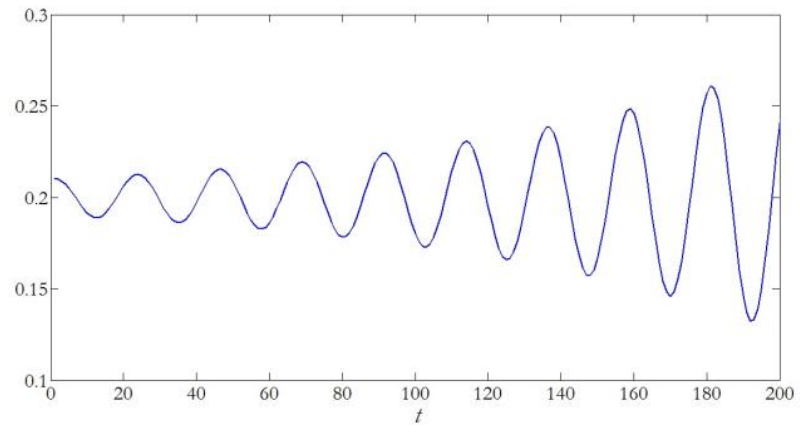

(c) Target net private debt-to-income ratio $\left(d_{P}^{T}\right)$

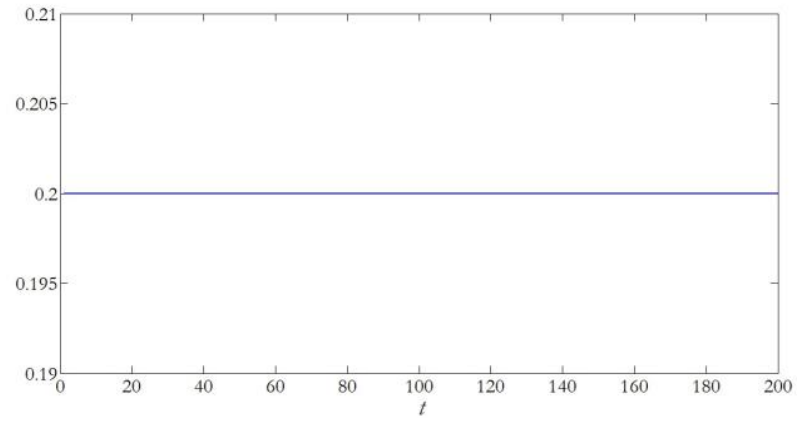

(e) Growth rate $\left(g_{Y}\right)$

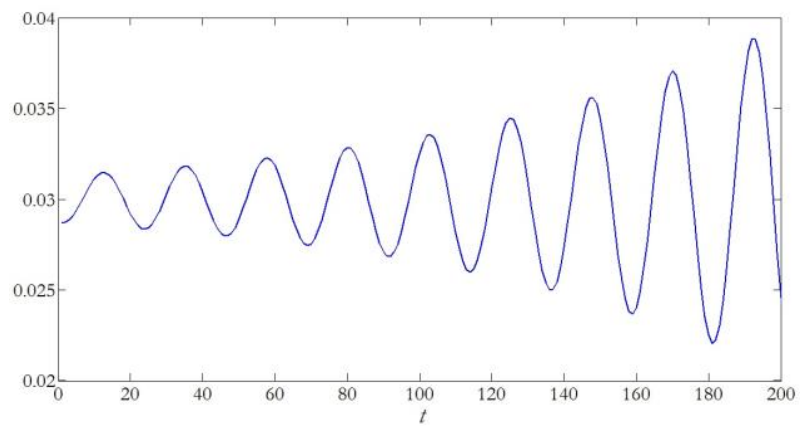

(b) Private sector's propensity to spend $(p)$

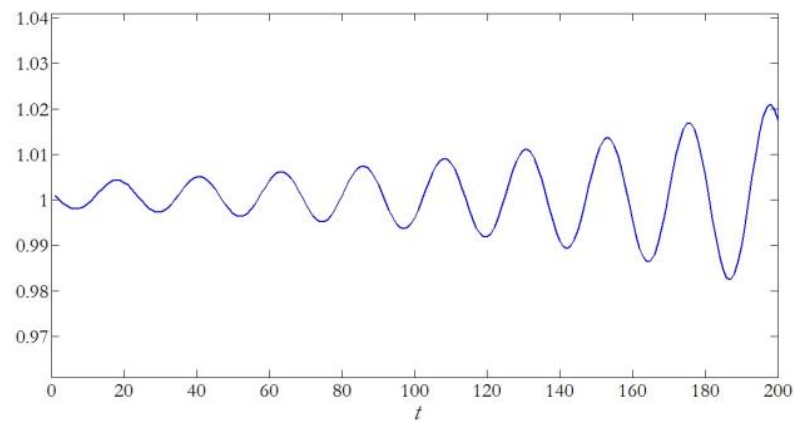

(d) Fiscal variables

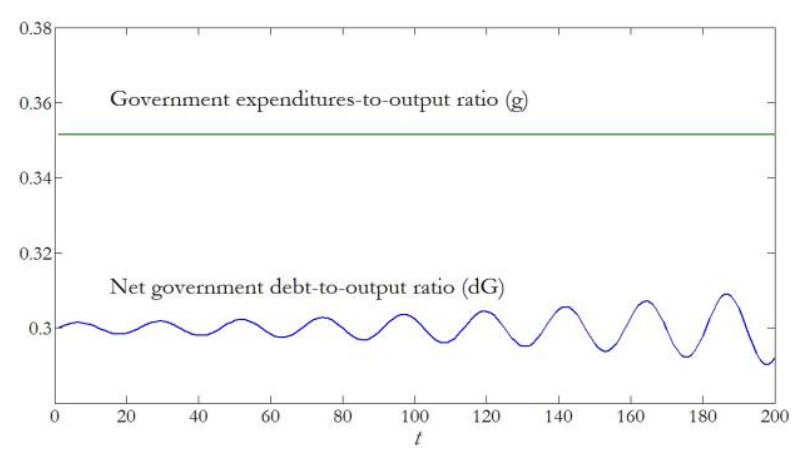

(f) Financial balances (in proportion of output)

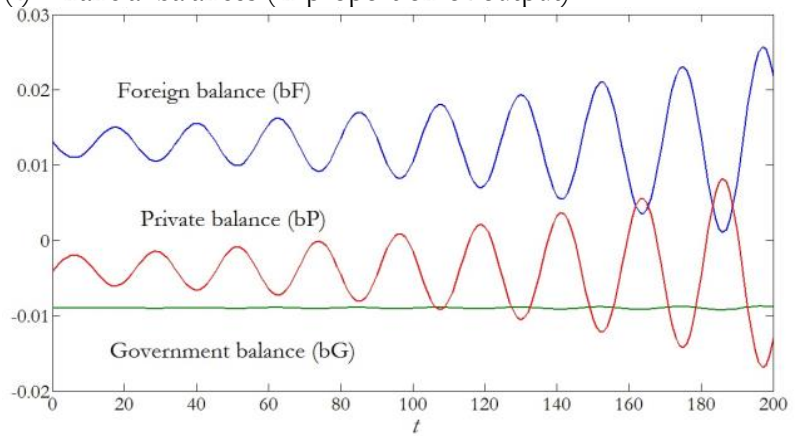


Since $g$ is constant in the 2D subsystem, net government indebtedness is exclusively driven by the 'growth effect': when economic growth is high (low) enough the net government debt-to-output ratio declines (increases). As shown in Fig. 2, this 'growth effect', which in the 2D subsystem is exclusively linked to the behaviour of the private sector, is sufficient to destabilise the net government debt-to-output ratio. Therefore, private sector's attempt to achieve its desired stock-flow norm can destabilise public indebtedness despite the fact the government sector is passive. However, the constancy of $g$ has as a result that the government financial balance does not change significantly relative to the other two balances. Consequently, any deterioration or improvement in the financial balance of the private sector is almost entirely mirrored in the balance of the foreign sector.

\section{The 3D subsystem: endogenising the targeted net private indebtedness}

We now allow the target net private debt-to-income ratio to change endogenously according to Eq. (17); $g$ is still kept at its steady-state value. The following proposition holds.

Proposition 2. Consider the system consisting of Eqs. (16), (17) and (22). Suppose that the steady state of the subsystem of Eqs. (16) and (22) is stable. Then, there exists a parameter value $\theta_{1}^{*}>0$ that satisfies the following properties:

(i) the steady state of the system is locally stable for all $\theta_{1} \in\left(0, \theta_{1}^{*}\right)$.

(ii) the steady state of the system is locally unstable for all $\theta_{1} \in\left(\theta_{1}^{*},+\infty\right)$.

(iii) the system undergoes a Hopf bifurcation at $\theta_{1}=\theta_{1}^{*}$ (in other words, there exists a limit cycle around the steady state for some range of the parameter value $\theta_{1}$ which is sufficiently close to $\theta_{1}^{*}$ ).

Proof. See Appendix C.

Proposition 2 suggests that the introduction of an endogenous change in the target net private debt-to-income ratio can transform an otherwise stable system of $d_{P}$ and $p$ into an unstable one. Instability arises when the responsiveness of the target net private debt-to-income ratio to changes in economic growth is sufficiently high. Fig. 3 illustrates this in our simulations. ${ }^{19}$ The figure refers to a private sector that has a net creditor benchmark position (similar results arise when a net debtor benchmark position is considered). It can be seen that the stability properties of the $3 \mathrm{D}$ subsystem change as $\theta_{1}$ increases: although the system is stable for low values of $\theta_{1}$, it becomes unstable when $\theta_{1}$ is higher than $\theta_{1}^{*} \approx 0.256$.

${ }^{19}$ For similar figures that show how changes in specific parameters affect the stability properties of dynamic systems, see Chiarella et al. (2012) and Nikolaidi (2014). 
Fig. 3. Dynamic adjustments of the $3 \mathrm{D}$ subsystem to a $5 \%$ positive shock in the net private debtto-income ratio for varying values of $\theta_{1}$; private sector in a net creditor benchmark position

$$
\left(d_{P}^{B}<0\right) \text {. }
$$

(a) Net private debt-to-income ratio $\left(d_{P}\right)$

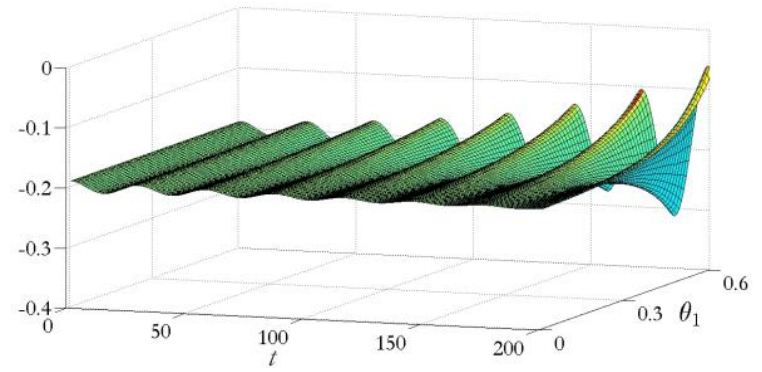

(c) Target net private debt-to-income ratio $\left(d_{P}^{T}\right)$

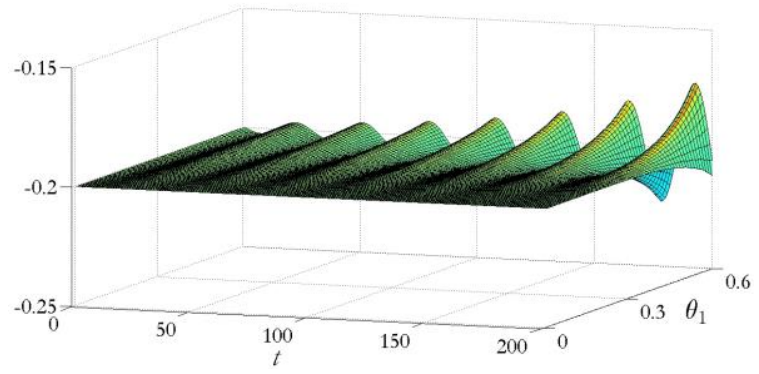

(e) Growth rate $\left(g_{Y}\right)$

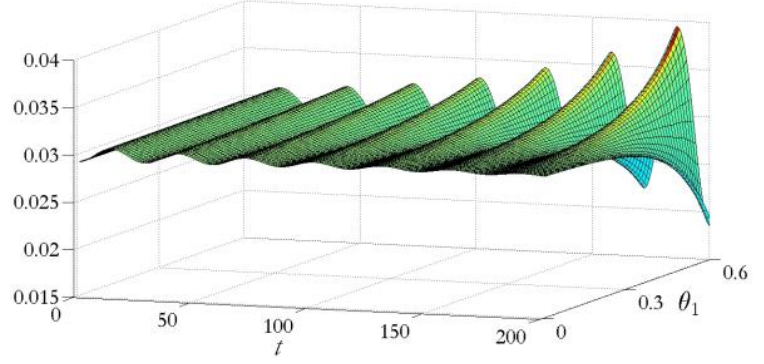

(b) Private sector's propensity to spend $(p)$

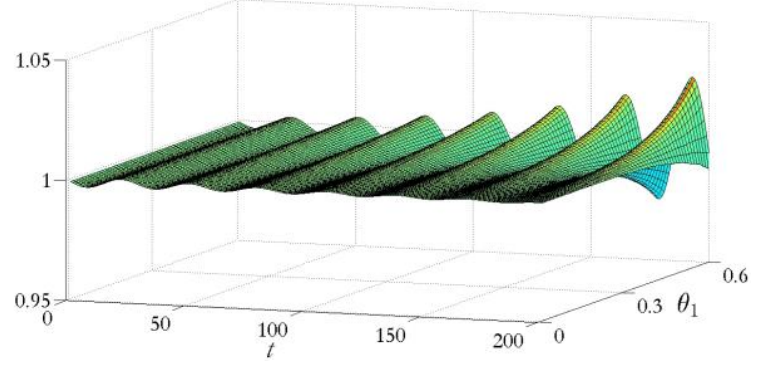

(d) Net government debt-to-output ratio $\left(d_{G}\right)$

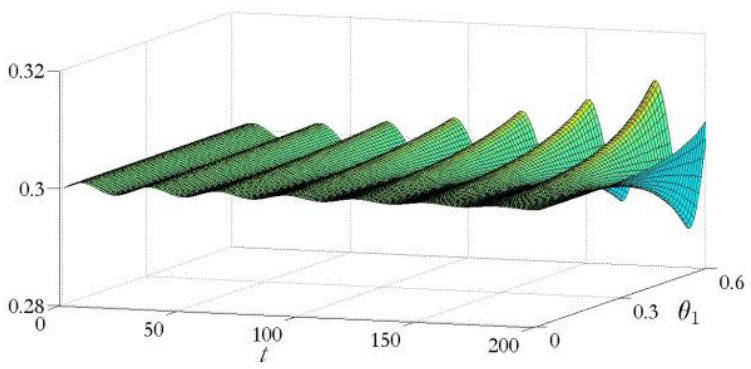

(f) Government balance-to-output ratio $\left(b_{G}\right)$

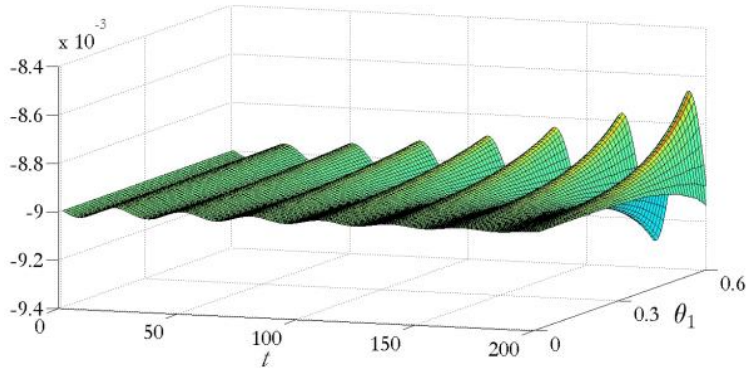


The underlying mechanism can be explained as follows. In periods of low growth, when net private indebtedness is high, the deterioration in borrowers' and lenders' expectations induces them to target a lower net debt ratio than the benchmark one $\left(d_{P}^{B}\right)$; recall that in the $2 \mathrm{D}$ subsystem $d_{P}^{T}=d_{P}^{B}$. Therefore, the difference between the actual and the target ratio increases, producing a greater decline in the propensity to spend (and therefore in economic growth) compared to the $2 \mathrm{D}$ subsystem. Inversely, in periods of high growth, in which net private indebtedness is low, the favourable expectations due to the good performance of the economy make the perceived risk lower. This leads to a higher target net debt ratio than the benchmark one and, hence, to a more important rise in the propensity to spend. This results in higher economic growth. The greater fluctuations in both the propensity to spend and economic growth are reflected in the law of motion of the net debt ratio. If $\theta_{1}$ is sufficiently high, these fluctuations ultimately lead to instability.

When $\theta_{1}=\theta_{1}^{*} \approx 0.256$, the endogeneity of the target net private debt-to-income ratio gives rise to a limit cycle. This is shown in Fig. 4 where the magnitude of the destabilising forces, associated with the changes in euphoria and the perceptions of risk, is slightly lower than the magnitude that is necessary to produce instability. The persistent cycles that are generated reveal that an otherwise stable Godley system can exhibit cyclical behaviour when it is combined with the Minskyan endogeneity of the stock-flow norm.

Fig. 4. Limit cycle in the 3D subsystem; private sector in a net creditor benchmark position

$$
\left(d_{P}^{B}<0\right) ; \theta_{1}=\theta_{1}^{*} \approx 0.256 \text {. }
$$

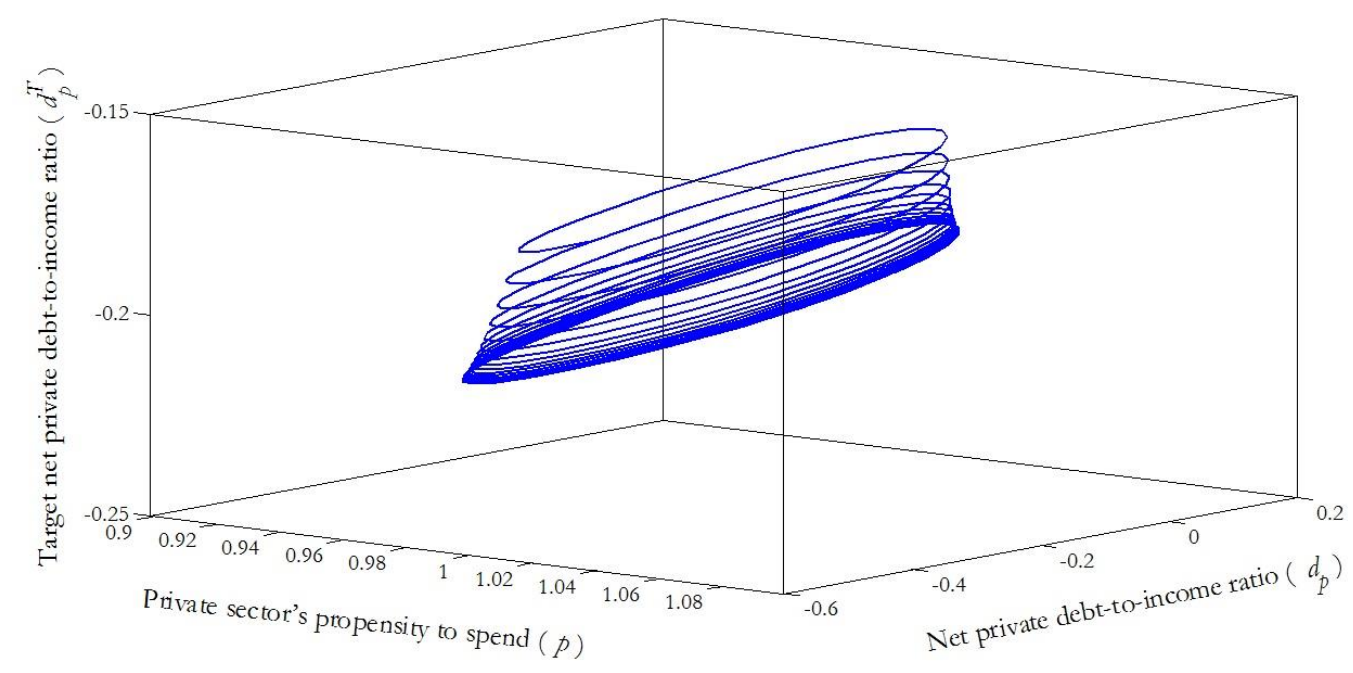

\section{The 5D system: introducing fiscal rules}

We now turn to examine how the stability of the macro system changes when fiscal rules are introduced. Fig. 5 illustrates the dynamic adjustment of the system when fiscal 
authorities adopt a Maastricht-type fiscal rule (Eq. 18a). Fig. 6 shows the dynamic adjustments when a Godley-Minsky fiscal rule is implemented (Eq. 18b). In both simulation exercises the parameter values that refer to Eqs. (16), (17) and (22) are the same with those used in the simulations presented in Fig. 3. Moreover, the same range of values for $\theta_{1}$ has been employed and the case in which $d_{P}^{B}<0$ has again been considered. This allows us to specify how the dynamic adjustments of the macro system are modified as a result of the introduction of fiscal rules.

Consider first the Maastricht-type fiscal rule. Comparing the simulation results between Fig. 3 and Fig. 5, it can be observed that instability increases as a result of the implementation of this fiscal rule: first, for high values of $\theta_{1}$ the cycles become much more intense; second, instability gradually arises even for low values of $\theta_{1}$. Intuitively, the following mechanisms are at play. Whenever economic growth is low (as a result of high net private indebtedness) there is a tendency for the net government debt-to-output ratio to increase. At some point during the period of low growth, the government debt ratio becomes higher than $d_{G}^{T}$. To guarantee fiscal discipline the government responds by reducing the expenditures-to-output ratio. This magnifies the contractionary effects that stem from the behaviour of the private sector: at a first place, economic growth is adversely affected by the decrease in $g$; at a second place, this additional decline in growth enhances the deterioration in the expectations reducing further $d_{P}^{T}$; other things equal, the divergence between $d_{P}$ and $d_{P}^{T}$ increases with destabilising effects on growth, private expenditures and net private debt. When the private sector has a net debtor benchmark position there is an additional channel through which the difference between $d_{P}$ and $d_{P}^{T}$ increases: lower growth resulted from fiscal stance places upward pressures on $d_{P}$. The inverse mechanisms are at work when economic growth is high. This implies that the Maastricht-type fiscal rule increases the amplitude of debt and economic cycles. ${ }^{20}$

Importantly, the induced instability refers not only to the private sector but also to the government sector. Fig. 5 illustrates that, as time passes, the Maastricht-type fiscal rule generates significant fluctuations in both the net government debt-to-output ratio and the government balance (as a proportion of output). These fluctuations are much more severe than those observed in Fig. 3. This result stems from the amplification of the economic cycles described above. Therefore, in an economy in which the private expenditures respond to changes in net private indebtedness and the targeted indebtedness is endogenous, the currently fashionable debt brake rules do not only seem to destabilise the private sector but they may also be ineffective in ensuring fiscal prudence. Actually, a paradox of debt result arises: the more the fiscal authorities attempt to target a specific government debt ratio, by adjusting the government expenditures, the more this ratio destabilises. ${ }^{21}$

${ }^{20}$ For the destabilising effects of Maastricht-type fiscal rules see also Charpe et al. (2011, ch. 9).

21 The potential application of the paradox of debt to the government sector has been briefly pointed out by Lavoie (2014, p. 19). 
Fig. 5. Dynamic adjustments of the $5 \mathrm{D}$ system to a $5 \%$ positive shock in the net private debt-toincome ratio for varying values of $\theta_{1}$; private sector in a net creditor benchmark position $\left(d_{P}^{B}<0\right)$; Maastricht-type fiscal rule.

(a) Net private debt-to-income ratio $\left(d_{P}\right)$

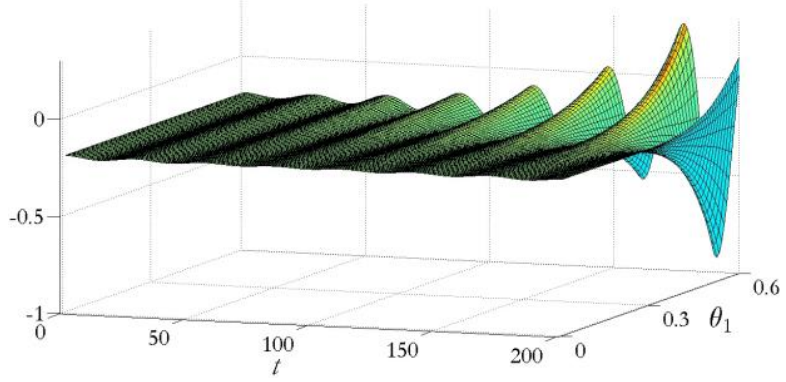

(c) Target net private debt-to-income ratio $\left(d_{P}^{T}\right)$

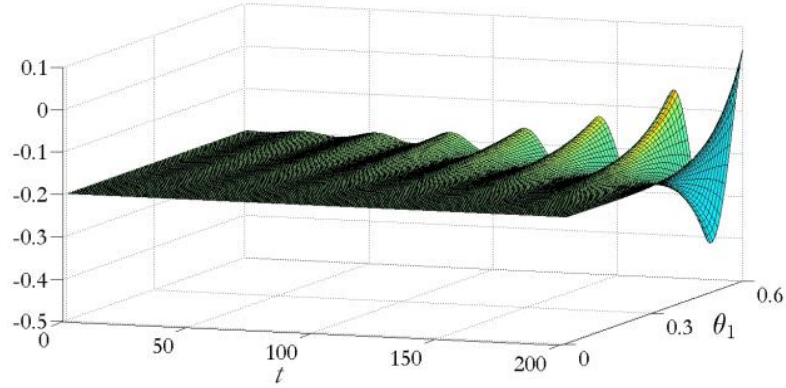

(e) Growth rate $\left(g_{Y}\right)$

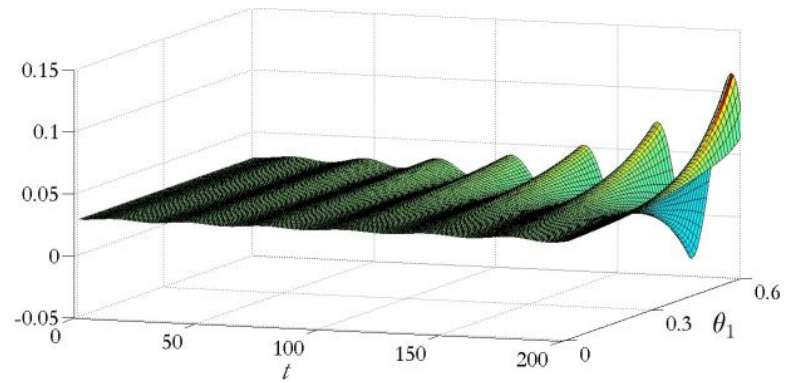

(b) Private sector's propensity to spend $(p)$

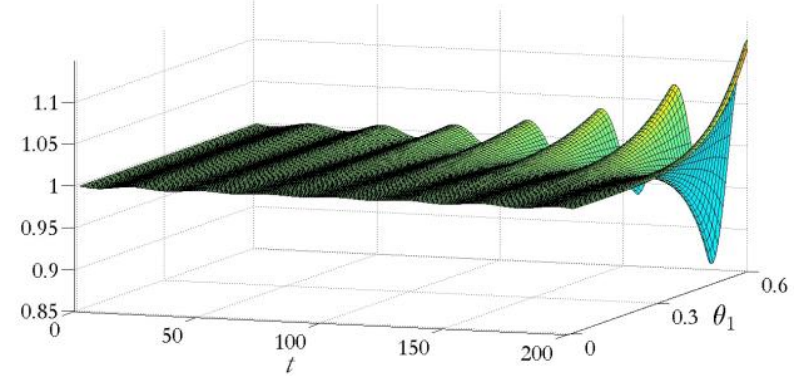

(d) Net government debt-to-output ratio $\left(d_{G}\right)$

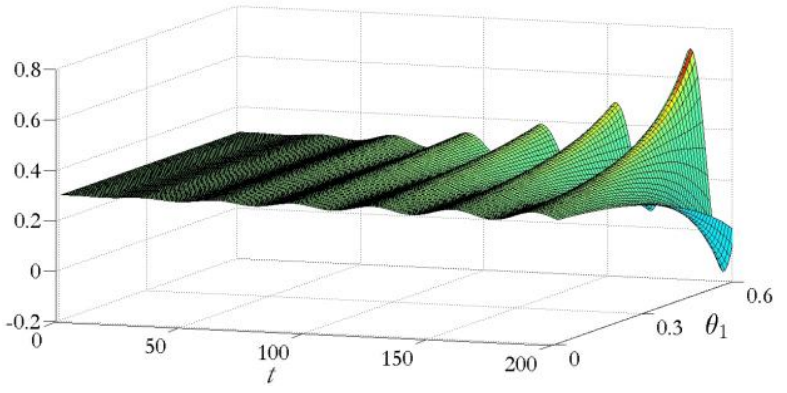

(f) Government balance-to-output ratio $\left(b_{G}\right)$

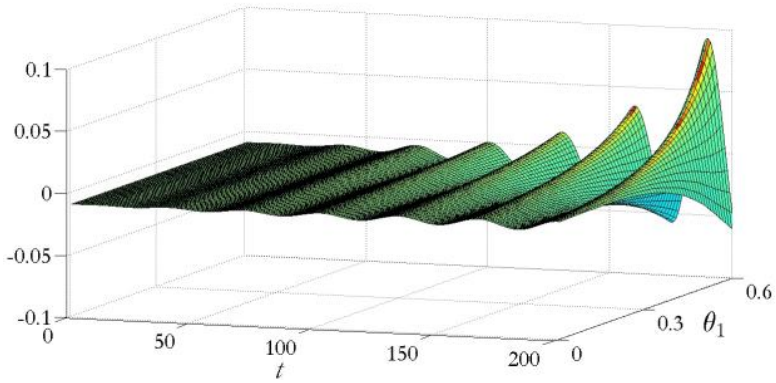


On the other hand, the Godley-Minsky fiscal rule suggested here is capable of stabilising both the private economy and the government sector for high values of $\theta_{1}$. Fig. 6 indicates this. After some fluctuations in the initial periods (which are much less intense than the fluctuations in Fig. 5) all macro variables converge towards their steady-state values. Economically, this can be explained as follows. When economic growth is low due to high net private indebtedness, the implementation of the Godley-Minsky fiscal rule produces a rise in the government expenditures-to-output ratio. This has favourable effects on economic growth since it tends to reduce the divergence between $d_{P}$ and $d_{P}^{T}$ by placing upward pressures on $d_{P}^{T}$. As alluded to before, the reduction of this divergence is conducive to stability. In high-growth phases the government expenditures-to-output ratio falls, slowing down the economic growth that is caused by the behaviour of the private sector. This again tends to reduce the difference between $d_{P}$ and $d_{P}^{T}$ via the impact on $d_{P}^{T}$. Consequently, fiscal policy reduces the amplitude of the cycles by suppressing the destabilising forces that stem from the endogenous changes in the desired margins of safety. This is also beneficial to the government sector itself. Since after some periods the fluctuations in economic growth decline, the same happens to the government balance (as a proportion of output) and the net government debt ratio. Therefore, although at a first place there might be some adverse developments in the fiscal performance, in the medium to the long run fiscal prudence is safeguarded under the Godley-Minsky fiscal rule.

Interestingly enough, the simulations in Fig. 6 indicate that the Godley-Minsky fiscal rule is not stabilising when $\theta_{1}$ is close to zero, i.e. when the target net debt ratio of the private sector does not change endogenously (or changes only slightly). The reason is that Fig. 6 refers to a private sector that has a net creditor benchmark position. As mentioned above, in this case a higher (lower) growth rate places upward (downward) pressures on the net debt ratio. Hence, the counter-cyclical effects of the Godley-Minsky fiscal rule are not conducive to stability. This, however, does not hold when the private sector has a net debtor benchmark position $\left(d_{P}^{B}>0\right)$. In this case, the Goldey-Minsky fiscal rule is stabilising even when $\theta_{1}$ is close to zero. 
Fig. 6. Dynamic adjustments of the $5 \mathrm{D}$ system to a $5 \%$ positive shock in the net private debt-toincome ratio for varying values of $\theta_{1}$; private sector in a net creditor benchmark position $\left(d_{P}^{B}<0\right)$; Godley-Minsky fiscal rule.

(a) Net private debt-to-income ratio $\left(d_{P}\right)$

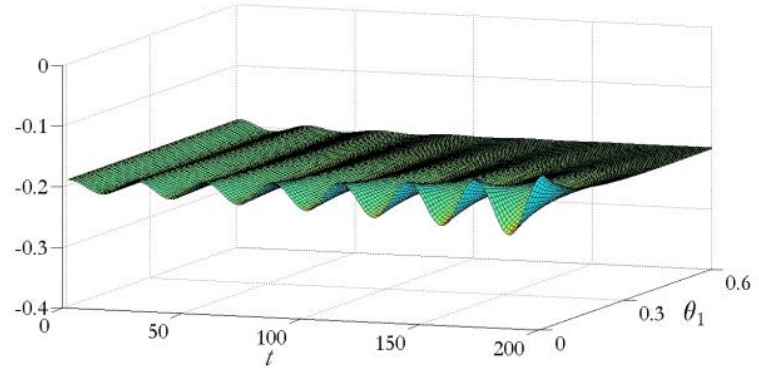

(c) Target net private debt-to-income ratio $\left(d_{P}^{T}\right)$

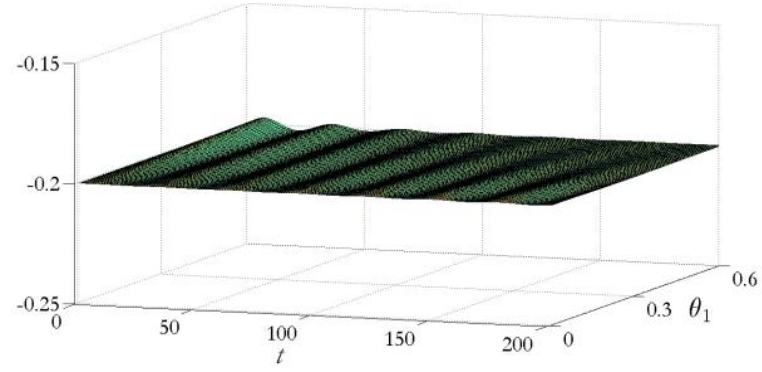

(e) Growth rate $\left(g_{Y}\right)$

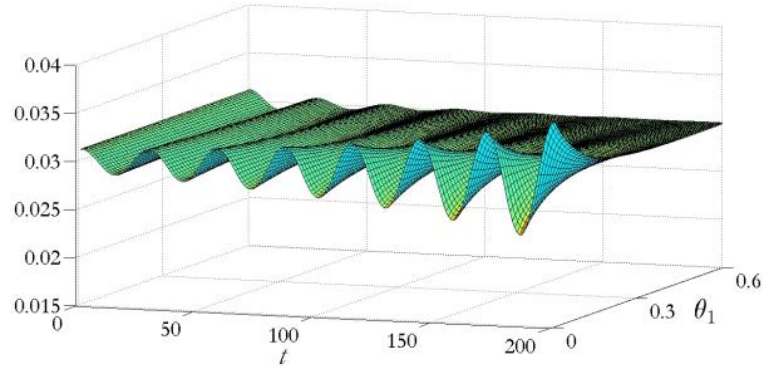

(b) Private sector's propensity to spend $(p)$

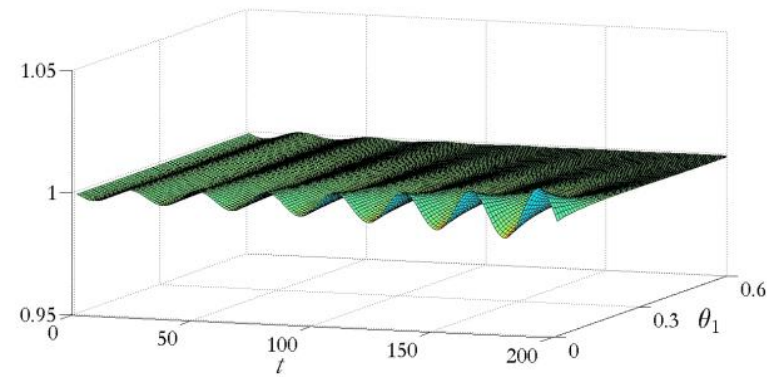

(d) Net government debt-to-output ratio $\left(d_{G}\right)$

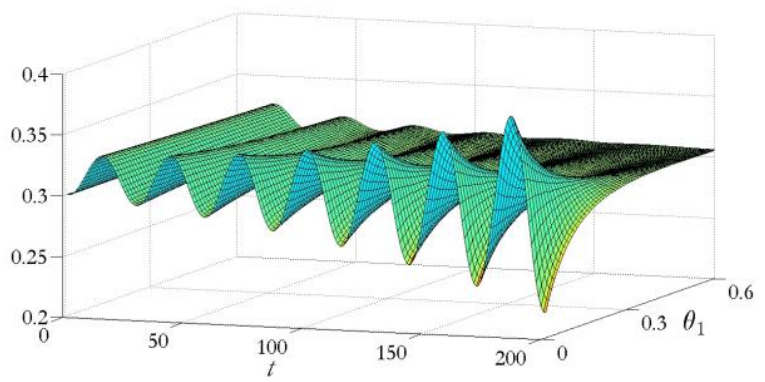

(f) Government balance-to-output ratio $\left(b_{G}\right)$

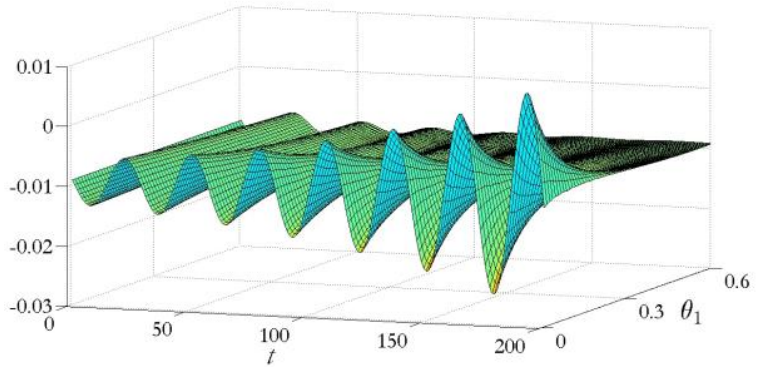


Fig. 7 compares the relationship of the net private debt ratio with the net government debt ratio between an economy that implements the Maastricht-type rule and an economy in which government expenditures change according to the Godley-Minsky rule. It can be observed that the nature of the debt cycles is very different in these economies. In the economy that implements the Maastricht-type rule, there are periods in which both the private and the government net debt ratio decline. However, these ostensibly tranquil periods of declining net indebtedness are followed by periods where both the government and the private net debt ratio increase. Contrariwise, under the Godley-Minsky fiscal rule the relationship between the two ratios is always inverse (before the steady state is reached): in periods in which the net private debt ratio declines (increases), the net government debt ratio increases (declines). This is the consequence of the attempts of the fiscal authorities to mitigate the contractionary (expansionary) effects that stem for the desire of the private sector to reduce (increase) its indebtedness.

Fig. 7. Relationship between net private and net government indebtedness in the 5D system; private sector in a net creditor benchmark position $\left(d_{P}^{B}<0\right) ; \theta_{1}=0.6$.

(a) Maastricht-type fiscal rule

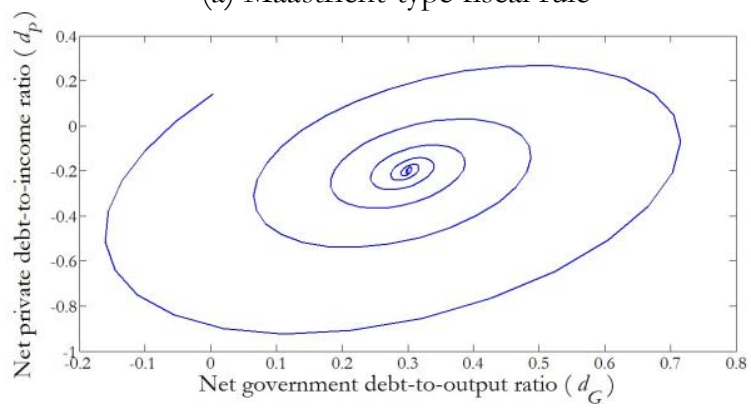

b) Godley-Minsky fiscal rule

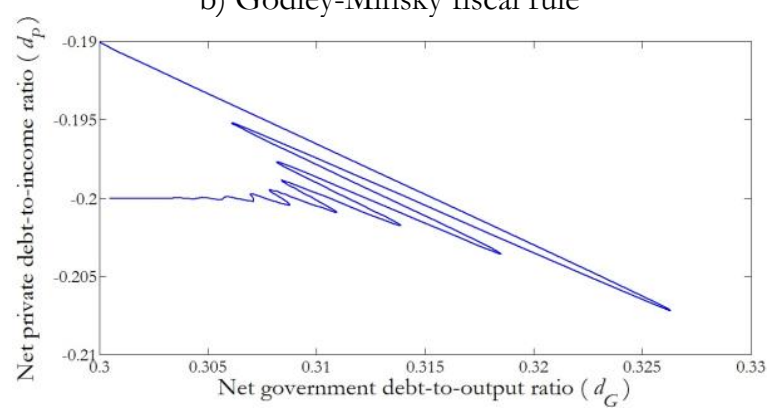

\section{Conclusion}

This paper developed a simple macrodynamic model that synthesises certain aspects of Godley's and Minsky's analytical frameworks. Using this model, it was first shown that Godley debt cycles are likely to arise as a result of the responsiveness of private sector's propensity to spend to divergences between the actual and the target net private debt ratio (the stock-flow norm). These cycles are generated when the private sector has a net debtor benchmark position. Instability emerges when the responsiveness of the propensity to spend is sufficiently high. This is a paradox of debt result: the more the private sector and its lenders attempt to put net private indebtedness under control, by adjusting private expenditures, the more the net private debt ratio destabilises. This result is associated with the economic growth consequences of this adjustment which have destabilising feedback effects on net private indebtedness.

Furthermore, the analysis indicated that when the target net private debt ratio is allowed to change endogenously via a Minsky mechanism an otherwise stable macro 
system can be transformed into an unstable one. This happens, in particular, when the expectations that determine the stock-flow norm are highly sensitive to the changes in economic performance. Godley-Minsky debt cycles can also be generated. These cycles are driven by the changes in euphoria and the perceptions of risk that affect Godley's stock-flow norm.

Lastly, the paper examined the implications of the developed framework for fiscal policy. The (de)stabilising effects of two different fiscal rules were compared. The first rule is a Maastricht-type fiscal rule according to which the government expenditures-tooutput ratio decreases (increases) when the net government debt ratio is higher (lower) than a target level. The second rule is a Godley-Minsky fiscal rule which states that fiscal authorities should increase (decrease) government expenditures when the private sector attempts to decrease (increase) its indebtedness. Simulation analysis illustrated that the Maastricht-type fiscal rule is destabilsing while the Godley-Minsky fiscal rule is stabilising. The paradox of debt appears to apply to the government sector: the more the fiscal authorities attempt to target a specific government debt ratio, by adjusting the government expenditures, the more this ratio destabilises. Moreover, the two fiscal rules produced different results as far the relationship between the private and the government net debt ratio is concerned. Under the Maastricht-type fiscal rule, there are periods in which these debt ratios move together producing both tranquil times of decreasing indebtedness and turbulent times of increasing indebtedness. Under the Godley-Minsky fiscal rule, the net government debt ratio always moves inversely with the net private debt ratio and, therefore, there are no periods in which private and government net indebtedness both increase.

The model of this paper and the results presented above bring to the fore the importance of Godley's and Minsky's perspectives on the inherent instability of the macroeconomy, the generation of debt cycles and the stabilising role of fiscal policy. Based on these perspectives, the paper provided a new look at the dynamics of the modern macroeconomies in which the financial relationships between the private, the government and the foreign sector play a crucial role. An important line of research would be to combine the Godley-Minsky cycles produced here -which focus on the role of sectoral debt- with the traditional Goodwin cycles -that concentrate on the intra-private sector relationships and the role of income distribution. ${ }^{22}$

${ }_{22}$ For the presentation of the Goodwin cycles and the combination of Goodwin's model with Minskyan dynamics see Keen (1995), Sordi and Vercelli (2014) and Stockhammer and Michell (2014). 


\section{Appendix A. Parameter values in the simulations}

\begin{tabular}{|c|c|c|}
\hline Parameter & Value & Justification \\
\hline Interest rate $(r)$ & 0.025 & $\begin{array}{l}\text { This is close to } 0.026 \text {, which is the unweighted average of the long-term } \\
\text { real interest rate for } 35 \text { EU and non-EU countries over the period 1961- } \\
2014 \text { (source: AMECO; code: ILRV). }\end{array}$ \\
\hline Growth rate of exports $\left(g_{X}\right)$ & 0.03 & $\begin{array}{l}\text { This is slightly higher than the interest rate, ensuring stability when the laws } \\
\text { of motion of debt ratios are examined in isolation (see Section 2). }\end{array}$ \\
\hline Taxes-to-output ratio $(\tau)$ & 0.35 & $\begin{array}{l}\text { This is close to 0.34, which is the uweighted average of the total tax } \\
\text { burden (excluding imputed social contributions), as a proportion of } \\
\text { GDP, for } 34 \text { EU and non-EU countries over the period 1975-2014 } \\
\text { (source: AMECO; code: UTAT). }\end{array}$ \\
\hline Imports-to-output ratio $(m)$ & 0.4 & $\begin{array}{l}\text { This is close to } 0.41 \text { which is the uw eighted average of the imports-to- } \\
\text { GDP ratio for } 43 \text { EU and non-EU countries over the period 1960-2014 } \\
\text { (source: AMECO; codes: UMGS, UVGD). }\end{array}$ \\
\hline $\begin{array}{l}\text { Target net government debt-to- } \\
\text { output ratio }\left(d_{G}^{T}\right)\end{array}$ & 0.3 & $\begin{array}{l}\text { This is equal to } 0.6 \text { minus } 0.3 ; 0.6 \text { is the maximum accepted value of the } \\
\text { gross public debt ratio according to the Maastricht criteria; } 0.3 \text { is the } \\
\text { average difference between gross and net goveernment debt ratio in } 27 \\
\text { advanced countries over the period } 2001-2012 \text { (source: IMF, World } \\
\text { Economic Outlook Database, April } 2015 \text { edition). }\end{array}$ \\
\hline $\begin{array}{l}\text { Benchmark net private debt-to- } \\
\text { income ratio }\left(d_{P}{ }^{B}\right) \text {; net debtor } \\
\text { position }\end{array}$ & 0.2 & $\begin{array}{l}\text { This has been chosen such that the steady-state private balance }\left(b_{P 0}\right) \text { is } \\
\text { slightly lower than } 0 \text {. }\end{array}$ \\
\hline $\begin{array}{l}\text { Benchmark net private debt-to- } \\
\text { income ratio }\left(d_{P}{ }^{B}\right) \text {; net creditor } \\
\text { position }\end{array}$ & -0.2 & $\begin{array}{l}\text { This has been chosen such that the steady-state private balance }\left(b_{P 0}\right) \text { is } \\
\text { slightly higher than } 0 \text {. }\end{array}$ \\
\hline $\begin{array}{l}\text { Responsiveness of the private } \\
\text { sector's propensity to spend to } \\
\text { the gap between the target and } \\
\text { the actual debt ratio }(\lambda)\end{array}$ & $\begin{array}{l}0.0153 \text { (Fig. 1) } \\
0.08 \text { (Fig. 2) } \\
0.05 \text { (Figs. 3-7) }\end{array}$ & $\begin{array}{l}\text { See the analysis of Figs. } 1 \text { and } 2 \text { in Section } 3 \text {. In Figs. 3, 5, } 6 \text { and } 7, \lambda \text { has } \\
\text { been chosen such that the values of the endogenous variables remain } \\
\text { within a relatively reasonable range when a } 5 \% \text { positive shock in the net } \\
\text { private debt-to-income ratio is imposed on the system. }\end{array}$ \\
\hline $\begin{array}{l}\text { Responsiveness of the private } \\
\text { sector's target debt ratio to the } \\
\text { gap between the actual and the } \\
\text { benchmark grow th rate }\left(\theta_{1}\right)\end{array}$ & $\begin{array}{l}0.2617 \text { (Fig. 4) } \\
0.6 \text { (Fig. 7) }\end{array}$ & $\begin{array}{l}\text { See the analysis of Fig. } 4 \text { in Section } 4 \text {. In Fig. } 7, \theta_{1} \text { has been chosen to be } \\
\text { higher than } \theta_{1}^{*} \text {, producing thereby an unstable } 3 \mathrm{D} \text { subsystem. }\end{array}$ \\
\hline $\begin{array}{l}\text { Responsiveness of the private } \\
\text { sector's target debt ratio to the } \\
\text { gap between the benchmark and } \\
\text { the target ratio }\left(\theta_{2}\right)\end{array}$ & 0.01 & $\begin{array}{l}\text { This has been chosen such that the values of the endogenous variables } \\
\text { remain within a relatively reasonable range when a } 5 \% \text { positive shock in } \\
\text { the net private debt-to-income ratio is imposed on the system. }\end{array}$ \\
\hline $\begin{array}{l}\text { Reaction parameter in the } \\
\text { Maastricht-type fiscal rule }(\mu)\end{array}$ & 0.04 & $\begin{array}{l}\text { This has been chosen such that the values of the endogenous variables } \\
\text { remain within a relatively reasonable range when a } 5 \% \text { positive shock in } \\
\text { the net private debt-to-income ratio is imposed on the system. }\end{array}$ \\
\hline $\begin{array}{l}\text { Reaction parameter in the } \\
\text { Godley-Minsky fiscal rule }(\kappa)\end{array}$ & 0.08 & $\begin{array}{l}\text { This has been chosen such that the values of the endogenous variables } \\
\text { remain within a relatively reasonable range when a } 5 \% \text { positive shock in } \\
\text { the net private debt-to-income ratio is imposed on the system. }\end{array}$ \\
\hline
\end{tabular}




\section{Appendix B. Proof of Proposition 1}

The Jacobian matrix of the $2 \mathrm{D}$ subsystem evaluated at the steady state is:

$$
J_{2 D}=\left(\begin{array}{ll}
J_{11} & J_{12} \\
J_{21} & J_{22}
\end{array}\right)
$$

where:

$$
\begin{aligned}
& J_{11}=\partial \dot{d}_{P} / \partial d_{P}=r-g_{X}+\frac{d_{P}^{B}(1-\tau) \lambda}{1+m-p_{0}(1-\tau)-g_{0}} \\
& J_{12}=\partial \dot{d}_{P} / \partial p=1 \\
& J_{21}=\partial \dot{p} / \partial d_{P}=-\lambda \\
& J_{22}=\partial \dot{p} / \partial p=0
\end{aligned}
$$

We have that:

$$
\begin{aligned}
& \operatorname{Tr}\left(J_{2 D}\right)=J_{11}+J_{22}=r-g_{X}+\frac{d_{P}^{B}(1-\tau) \lambda}{1+m-p_{0}(1-\tau)-g_{0}} \\
& \operatorname{Det}\left(J_{2 D}\right)=J_{11} J_{22}-J_{21} J_{12}=\lambda>0
\end{aligned}
$$

\section{Proof of (a):}

If $d_{P}^{B}<0$, then $\operatorname{Tr}\left(J_{2 D}\right)<0$; recall that $g_{X}>r$ and $1+m-p_{0}(1-\tau)-g_{0}>0$ (see Section 2$)$. Since $\operatorname{Det}\left(J_{2 D}\right)$ is always positive, the steady state is locally stable.

\section{Proof of (b-i):}

If $d_{P}^{B}>0$, then $\operatorname{Tr}\left(J_{2 D}\right)<0$ for sufficiently low values of $\lambda$. By setting $\operatorname{Tr}\left(J_{2 D}\right)=0$, we can find the critical value for $\lambda$ below which $\operatorname{Tr}\left(J_{2 D}\right)<0$ :

$$
\lambda^{*}=-\frac{\left(r-g_{X}\right)\left(1+m-p_{0}(1-\tau)-g_{0}\right)}{d_{P}^{B}(1-\tau)}>0
$$

Therefore, the steady state is locally stable when $\lambda<\lambda^{*}$.

\section{Proof of (b-ii):}

If $d_{P}^{B}>0$ and $\lambda>\lambda^{*}$, we have that $\operatorname{Tr}\left(J_{2 D}\right)>0$. Hence, since $\operatorname{Det}\left(J_{2 D}\right)$ is always positive, the steady state is locally unstable. 


\section{Proof of (b-iii):}

At $\lambda=\lambda^{*}, \operatorname{Det}\left(J_{2 D}\right)>0$ and $\operatorname{Tr}\left(J_{2 D}\right)=0$. This implies that the characteristic equation of the system has a pair of pure imaginary roots. Furthermore, we have that:

$$
\left.\frac{d}{d \lambda}(\operatorname{Tr}(\lambda))\right|_{\lambda=\lambda^{*}}=\left.\frac{d}{d \lambda}\left(\frac{d_{P}^{B}(1-\tau) \lambda}{1+m-p_{0}(1-\tau)-g_{0}}\right)\right|_{\lambda=\lambda^{*}}=\frac{d_{P}^{B}(1-\tau)}{1+m-p_{0}(1-\tau)-g_{0}}>0
$$

This means that at $\lambda=\lambda^{*}$ the real part of the imaginary roots is not stationary with respect to changes in $\lambda$ (note that the trace of the Jacobian matrix represents the real part of the roots). Therefore, the conditions for the existence of a Hopf bifurcation point are satisfied.

\section{Appendix C. Proof of Proposition 2}

The Jacobian matrix of the 3D subsystem, evaluated at the steady state, is:

$$
J_{3 D}=\left(\begin{array}{lll}
J_{11} & J_{12} & J_{13} \\
J_{21} & J_{22} & J_{23} \\
J_{31} & J_{32} & J_{33}
\end{array}\right)
$$

where:

$$
\begin{aligned}
& J_{11}=\partial \dot{d}_{P} / \partial d_{P}=r-g_{X}+\frac{d_{P}^{B}(1-\tau) \lambda}{1+m-p_{0}(1-\tau)-g_{0}} \\
& J_{12}=\partial \dot{d}_{P} / \partial p=1 \\
& J_{13}=\partial \dot{d}_{P} / \partial d_{P}^{T}=-\frac{(1-\tau) d_{P}^{B} \lambda}{1+m-p_{0}(1-\tau)-g_{0}} \\
& J_{21}=\partial \dot{p} / \partial d_{P}=-\lambda \\
& J_{22}=\partial \dot{p} / \partial p=0 \\
& J_{23}=\partial \dot{p} / \partial d_{P}^{T}=\lambda \\
& J_{31}=\partial \dot{d}_{P}^{T} / \partial d_{P}=-\frac{(1-\tau) \lambda \theta_{1}}{1+m-p_{0}(1-\tau)-g_{0}} \\
& J_{32}=\partial \dot{d}_{P}^{T} / \partial p=0 \\
& J_{33}=\partial \dot{d}_{P}^{T} / \partial d_{P}^{T}=\frac{\theta_{1}(1-\tau) \lambda}{1+m-p_{0}(1-\tau)-g_{0}}-\theta_{2}
\end{aligned}
$$

The characteristic equation of the system is: 
$\Phi(d)=d^{3}+a_{1} d^{2}+a_{2} d+a_{3}=0$

We have that:

(i) $a_{1}=-\left(J_{11}+J_{22}+J_{33}\right)=-\operatorname{Tr}\left(J_{2 D}\right)+\theta_{2}-\frac{\theta_{1}(1-\tau) \lambda}{1+m-p_{0}(1-\tau)-g_{0}}=\Omega_{1}+\Omega_{2} \theta_{1}$,

where $\Omega_{1}=-\operatorname{Tr}\left(J_{2 D}\right)+\theta_{2}$ and $\Omega_{2}=-\frac{(1-\tau) \lambda}{1+m-p_{0}(1-\tau)-g_{0}}<0$.

(ii) $a_{2}=\left|\begin{array}{ll}J_{11} & J_{12} \\ J_{21} & J_{22}\end{array}\right|+\left|\begin{array}{ll}J_{11} & J_{13} \\ J_{31} & J_{33}\end{array}\right|+\left|\begin{array}{ll}J_{22} & J_{23} \\ J_{32} & J_{33}\end{array}\right|$ or

$a_{2}=\lambda+\operatorname{Tr}\left(J_{2 D}\right)\left(\frac{\theta_{1}(1-\tau) \lambda}{1+m-p_{0}(1-\tau)-g_{0}}-\theta_{2}\right)-\frac{\theta_{1}(1-\tau)^{2} \lambda^{2} d_{P}^{B}}{\left(1+m-p_{0}(1-\tau)-g_{0}\right)^{2}}=\Omega_{3}+\Omega_{4} \theta_{1}$,

where $\Omega_{3}=\lambda-\operatorname{Tr}\left(J_{2 D}\right) \theta_{2}$ and $\Omega_{4}=\frac{\left(r-g_{X}\right) \lambda(1-\tau)}{1+m-p_{0}(1-\tau)-g_{0}}<0$.

(iii) $a_{3}=-\operatorname{Det}\left(J_{3 D}\right)=-\left|\begin{array}{lll}J_{11} & J_{12} & J_{13} \\ J_{21} & J_{22} & J_{23} \\ J_{31} & J_{32} & J_{33}\end{array}\right|=\lambda \theta_{2}>0$

(iv) $b=a_{1} a_{2}-a_{3}=\left(\Omega_{1}+\Omega_{2} \theta_{1}\right)\left(\Omega_{3}+\Omega_{4} \theta_{1}\right)-a_{3}$.

Since we consider the case in which the steady state of the $2 \mathrm{D}$ subsystem is stable, we have that $\operatorname{Tr}\left(J_{2 D}\right)<0$ and, hence, $\Omega_{1}, \Omega_{3}>0$. Since $\Omega_{2}, \Omega_{4}<0, a_{1}$ and $a_{2}$ are a negative function of $\theta_{1}$. By setting $a_{1}=0$ and solving for $\theta_{1}$, we obtain $\theta_{1}^{a_{1}}=-\Omega_{1} / \Omega_{2}>0$. Hence, for $\theta_{1}<\theta_{1}^{a_{1}}, a_{1}$ is positive. By setting $a_{2}=0$ and solving for $\theta_{1}$, we obtain $\theta_{1}^{a_{2}}=-\Omega_{3} / \Omega_{4}>0$. Hence, for $\theta_{1}<\theta_{1}^{a_{2}}, a_{2}$ is positive. Note that $a_{3}$ is independent of $\theta_{1}$.

The expression for $b$ can be written as:

$$
b=\Omega_{2} \Omega_{4} \theta_{1}^{2}+\left(\Omega_{1} \Omega_{4}+\Omega_{2} \Omega_{3}\right) \theta_{1}+\Omega_{1} \Omega_{3}-a_{3}
$$

The quadratic equation $b=0$ has two roots:

$$
\theta_{1}^{b_{1}}, \theta_{1}^{b_{2}}=\frac{-\left(\Omega_{1} \Omega_{4}+\Omega_{2} \Omega_{3}\right) \pm \sqrt{\left(\Omega_{1} \Omega_{4}+\Omega_{2} \Omega_{3}\right)^{2}-4 \Omega_{2} \Omega_{4}\left(\Omega_{1} \Omega_{3}-a_{3}\right)}}{2 \Omega_{2} \Omega_{4}}
$$


It can be proved that: $\left(\Omega_{1} \Omega_{4}+\Omega_{2} \Omega_{3}\right)^{2}-4 \Omega_{2} \Omega_{4}\left(\Omega_{1} \Omega_{3}-a_{3}\right)=\left(\Omega_{1} \Omega_{4}-\Omega_{2} \Omega_{3}\right)^{2}+4 \Omega_{2} \Omega_{4} a_{3}>0$. Hence, the two roots are real and can be re-written as:

$\theta_{1}^{b_{1}}, \theta_{1}^{b_{2}}=\frac{-\left(\Omega_{1} \Omega_{4}+\Omega_{2} \Omega_{3}\right) \pm \sqrt{\left(\Omega_{1} \Omega_{4}-\Omega_{2} \Omega_{3}\right)^{2}+4 \Omega_{2} \Omega_{4} a_{3}}}{2 \Omega_{2} \Omega_{4}}$

The quadratic equation can be expressed as:

$b=\Omega_{2} \Omega_{4}\left(\theta_{1}-\theta_{1}^{b_{1}}\right)\left(\theta_{1}-\theta_{1}^{b_{2}}\right)=0$

According to Vieta's formulas, $\theta_{1}^{b_{1}}+\theta_{1}^{b_{2}}=-\left(\Omega_{1} \Omega_{4}+\Omega_{2} \Omega_{3}\right) /\left(\Omega_{2} \Omega_{4}\right)>0$ and $\theta_{1}^{b_{1}} \theta_{1}^{b_{2}}=\left(\Omega_{1} \Omega_{3}-a_{3}\right) /\left(\Omega_{2} \Omega_{4}\right)>0$ (it can be proved that $\left.\Omega_{1} \Omega_{3}-a_{3}>0\right)$. Therefore, $\theta_{1}^{b 1}$ and $\theta_{1}^{b 2}$ are both positive. Assuming $\theta_{1}^{b 1}<\theta_{1}^{b 2}$, it follows that $b>0$ for all $\theta_{1} \in\left(-\propto, \theta_{1}^{b 1}\right) \cup\left(\theta_{1}^{b 2},+\infty\right)$ and $b<0$ for all $\theta_{1} \in\left(\theta_{1}^{b 1}, \theta_{1}^{b 2}\right)$.

It can also be proved that $\theta_{1}^{b 1}<\theta_{1}^{a 1}<\theta_{1}^{b 2}$ and $\theta_{1}^{b 1}<\theta_{1}^{a 2}<\theta_{1}^{b 2}$ (the proof is available upon request).

\section{Proof of (i):}

Suppose that $\theta_{1}^{*}=\theta_{1}^{b 1}$. If $\theta_{1}<\theta_{1}^{*}$, then $a_{1}, a_{2}, a_{3}, b>0$. Therefore, according to the Routh-Hurwitz conditions, the steady state of the $3 \mathrm{D}$ subsystem is locally stable.

\section{Proof of (ii):}

Suppose that $\theta_{1}^{*}=\theta_{1}^{b 1}$. If $\theta_{1}>\theta_{1}^{*}$, then we have two cases. In the first case, $\theta_{1}<\theta_{1}^{b 2}$, implying that $b<0$. In the second case, $\theta_{1} \geq \theta_{1}^{b 2}$, implying that $b \geq 0$ and $a_{1}, a_{2}<0$. Therefore, in both cases at least one of the Routh-Hurwitz conditions is violated and, hence, the steady state of the $3 \mathrm{D}$ subsystem is locally unstable.

\section{Proof of (iii):}

Suppose that $\theta_{1}^{*}=\theta_{1}^{b 1}$. At $\theta_{1}=\theta_{1}^{*}$, it holds that $a_{1}, a_{2}, a_{3}>0$ and $b=0$. This implies that the characteristic equation has a pair of pure imaginary roots and a negative real root. Therefore, to prove that $\theta_{1}^{*}$ is a Hopf bifurcation point, it suffices to show that $\left.\frac{\partial \Gamma\left(\theta_{1}\right)}{\partial \theta_{1}}\right|_{\theta_{1}=\theta_{1}^{*}} \neq 0$, where $\Gamma$ is the real part of the two imaginary roots. Asada and Semmler 
(1995) have proved that the condition $\left.\frac{\partial \Gamma\left(\theta_{1}\right)}{\partial \theta_{1}}\right|_{\theta_{1}=\theta_{1}^{*}} \neq 0$ is equivalent to the condition $\left.\frac{\partial b\left(\theta_{1}\right)}{\partial \theta_{1}}\right|_{\theta_{1}=\theta_{1}^{*}} \neq 0$ (see also Yoshida and Asada, 2007).

We have that:

$\frac{\partial b\left(\theta_{1}\right)}{\partial \theta_{1}}=2 \Omega_{2} \Omega_{4} \theta_{1}+\left(\Omega_{1} \Omega_{4}+\Omega_{2} \Omega_{3}\right)$

Since $\theta_{1}^{*}=\theta_{1}^{b_{1}}=\frac{-\left(\Omega_{1} \Omega_{4}+\Omega_{2} \Omega_{3}\right)-\sqrt{\left(\Omega_{1} \Omega_{4}-\Omega_{2} \Omega_{3}\right)^{2}+4 \Omega_{2} \Omega_{4} a_{3}}}{2 \Omega_{2} \Omega_{4}}$, we get:

$\left.\frac{\partial b\left(\theta_{1}\right)}{\partial \theta_{1}}\right|_{\theta_{1}=\theta_{1}^{*}}=-\sqrt{\left(\Omega_{1} \Omega_{4}-\Omega_{2} \Omega_{3}\right)^{2}+4 \Omega_{2} \Omega_{4} a_{3}}<0$. 


\section{References}

Asada, T., Semmler, W., 1995. Growth and finance: an intertemporal model. Journal of Macroeconomics 17 (4), 623-649.

Bezemer, D.J., 2010. Understanding financial crisis through accounting models. Accounting, Organizations and Society 35 (7), 676-688.

Bhattacharya, S., Goodhart, C.A.E., Tsomocos, D.P., Vardoulakis, A.P. 2015. A reconsideration of Minsky's financial instability hypothesis. Journal of Credit, Money and Banking 47 (5), 931-973.

Borio, C., 2013. The financial cycle and macroeconomics: what have we learned? Journal of Banking and Finance 45, 182-198.

Brecht, M., Tober, S., van Treeck, T., Truger, A., 2012. Squaring the circle in Euro land? some remarks on the stability programmes 2010-13, in: Papadimitriou, D.B., Zezza, G. (Eds.). Contributions in Stock-flow Modeling: Essays in Honor of Wynne Godley. Palgrave Macmillan, Basingstoke, UK and New York, US, pp. 349-376.

Charpe, M., Chiarella, C., Flaschel, P., Semmler, W., 2011. Financial Assets, Debt and Liquidity Crises: a Keynesian Approach. Cambridge University Press, New York.

Chiarella, C., di Guilmi, C., 2011. The financial instability hypothesis: a stochastic microfoundation framework. Journal of Economic Dynamics and Control 35, 11511171.

Chiarella, C., Flaschel, P., Hartmann, F., Proaño, C.R., 2012. Stock market booms, endogenous credit creation and the implications of broad and narrow banking for macroeconomic stability. Journal of Economic Behavior and Organization 83, 410423.

Chortareas, G., 2013. Fiscal rules in monetary unions. Journal of Post Keynesian Economics 36 (1), 85-104.

Dos Santos, C.H., Macedo e Silva, A.C., 2010. Revisiting 'New Cambridge': the three financial balances in a general stock-flow consistent applied modeling strategy. Working Paper 594, Levy Economics Institute of Bard College.

Eggertsson, G.B., Krugman, P., 2012. Debt, deleveraging, and the liquidity trap: a Fischer-Minsky-Koo approach. The Quarterly Journal of Economics 127 (3), 14691513.

Godley, W., 1995. US foreign trade, the budget deficit and strategic policy problems: a background brief. Working Paper 138, Levy Economics Institute of Bard College.

Godley, W., 1999. Seven unsustainable processes: medium-term prospects and policies for the United States and the World. Special Report, Levy Economics Institute of Bard College.

Godley, W., 2003. The US economy: a changing strategic predicament. Strategic Analysis, Levy Economics Institute of Bard College.

Godley, W., 2005. Some unpleasant American arithmetic. Policy Note 5, Levy Economics Institute of Bard College.

Godley, W., Cripps, F., 1983. Macroeconomics, Oxford University Press, Oxford.

Goldey, W., Lavoie, M., 2007. Fiscal policy in a stock-flow consistent (SFC) model. Journal of Post Keynesian Economics 30 (1), 79-100. 
Godley, W., Hannsgen, G., Papadimitriou, D.B., Zezza, G., 2007. The US economy: is there a way out of the woods?. Strategic Analysis, Levy Economics Institute of Bard College.

Godley, W., Papadimitriou, D.B., Dos Santos, C.H., Zezza, G., 2005. The United States and her creditors: Can the symbiosis last?. Strategic Analysis, Levy Economics Institute of Bard College.

Hein, E., 2007. Interest rate, debt, distribution and capital accumulation in a PostKaleckian model. Metroeconomica 58 (2), 310-339.

IMF. 2009. Fiscal rules - anchoring expectations for sustainable public finances, IMF.

Keen, S., 1995. Finance and economic breakdown: modeling Minsky's 'financial instability hypothesis'. Journal of Post Keynesian Economics 17 (4), 607-635.

Keen, S., 2013. A monetary Minsky model of the Great Moderation and the Great Recession. Journal of Economic Behavior and Organization 86, 221-235.

Koo, R.C., 2013. Balance sheet recession as the 'other half of macroeconomics. European Journal of Economics and Economics Policies: Intervention 10 (2), 136-157.

Kregel, J., 1997. Margins of safety and weight of the argument in generating financial fragility. Journal of Economic Issues 31 (2), 543-548.

Kregel, J., 2011. Debtors' crisis or creditors' crisis? Who pays for the European sovereign and subprime mortgage losses?. Public Policy Brief 121, Levy Economics Institute of Bard College.

Lavoie, M., 1995. Interest rates in Post-Keynesian models of growth and distribution. Metroeconomica 46 (2), 146-177.

Lavoie, M., 2014. Post-Keynesian Economics: New Foundations. Edward Elgar, Cheltenham, UK and Northampton, MA, USA.

Leite, F.P., 2015. Taking Godley's ratios seriously. Metroeconomica 66 (3), 508-533.

Martin, B., 2008. Fiscal policy in a stock-flow consistent model: a comment. Journal of Post Keynesian Economics 30 (4), 649-667.

Martin, B., 2012. A new look at New Cambridge: will the UK private expenditure function stand up?, in: Papadimitriou, D.B., Zezza, G. (Eds.). Contributions in Stock-flow Modeling: Essays in Honor of Wynne Godley. Palgrave Macmillan, Basingstoke, UK and New York, US, pp. 76-124.

Minsky, H.P., 1975. John Maynard Keynes. Columbia University Press, New York.

Minsky, H.P., 1982. Inflation, Recession and Economic Policy. M.E. Sharpe, Armonk, New York.

Minsky, H.P., 2008 [1986]. Stabilizing an Unstable Economy. Mc Graw Hill, New York.

Nikolaidi, M., 2014. Margins of safety and instability in a macrodynamic model with Minskyan insights. Structural Change and Economic Dynamics 31, 1-16.

Palley, T.I., 2011. A theory of Minsky super-cycles and financial crises. Contributions to Political Economy 30, 31-46.

Pasarella, M., 2012. A simplified stock-flow consistent dynamic model of the systemic financial fragility in the 'New Capitalism'. Journal of Economic Behavior and Organization 83, 570- 582.

Ryoo, S., 2010. Long waves and short cycles in a model of endogenous financial fragility. Journal of Economic Behaviour and Organization 74, 163-186. 
Ryoo, S., 2013a. Minsky cycles in Keynesian models of growth and distribution. Review of Keynesian Economics, 1 (1), 37-60.

Ryoo, S., 2013b. The paradox of debt and Minsky's financial instability hypothesis. Metroeconomica 64 (1), 1-24.

Sawyer, M., 2011. UK fiscal policy after the global financial crisis. Contributions to Political Economy 30, 13-29.

Schaechter, A., Kinda, T., Budina, N., Weber, A., 2012. Fiscal rules in response to the crisis-toward the next-generation rules: a new dataset. Working Paper 12/187, IMF.

Shaikh, A., 2012. Three balances and twin deficits: Godley versus Ruggles and Ruggles, in: Papadimitriou, D.B., Zezza, G. (Eds.). Contributions in Stock-flow Modeling: Essays in Honor of Wynne Godley. Palgrave Macmillan, Basingstoke, UK and New York, US, pp. 125-153.

Sordi, S. Verceli, A., 2012. Hereogeneous expectations and strong uncertainty in a Minskyian model of financial fluctuations. Journal of Economic Behavior and Organization, 83, 544-557.

Sordi, S. Verceli, A., 2014. Unemployment, income distribution and debt-financed investment in a growth cycle model. Journal of Economic Dynamics and Control 48, 325-348.

Steindl, J., 1976 [1952]. Maturity and Stagnation in American Capitalism. Monthly Review Press, New York and London.

Stockhammer, E., Michell, J., 2014. Pseudo-Goodwin cycles in a Minsky model. Working Paper 1405, Post-Keynesian Economics Study Group.

Tymoigne, E., 2009. Central Banking, Asset Prices and Financial Fragility. Routledge, London and New York.

Tymoigne, E., Wray, R.L., 2014. The Rise and Fall of Money Manager Capitalism: Minsky's Half Century from World War Two to the Great Recession. Routledge, London and New York.

Vercelli, A., 2011. A perspective on Minsky moments: Revisiting the core of the financial instability hypothesis. Review of Political Economy 23 (1), 49-67.

Whalen, C., 2008. Understanding the credit crunch as a Minsky moment. Challenge 51 (1), 91-109.

Wolf, M., 2008. The end of lightly regulated capital has come far closer. Financial Times, 16 September 2008 (http://www.ft.com/cms/s/0/49a481fe-8406-11dd-bf00000077b07658.html\#axzz2znOSqOY4, last accessed on 4 August 2015).

Wolf, M., 2012. The balance sheet recession in the US. Financial Times, 19 June 2012 (http://blogs.ft.com/martin-wolf-exchange/2012/07/19/the-balance-sheet-recessionin-the-us/, last accessed on 4 August 2015).

Wray, L.R., 2011. Financial Keynesianism and market instability. Working Paper 653, Levy Economics Institute of Bard College.

Wray, L.R., 2012. Godley got it right, in: Papadimitriou, D.B., Zezza, G. (Eds.). Contributions in Stock-flow Modeling: Essays in Honor of Wynne Godley. Palgrave Macmillan, Basingstoke, UK and New York, US, pp. 36-62.

Yoshida, H., Asada, T., 2007. Dynamic analysis of policy lag in a Keynes-Goodwin model: stability, instability, cycles and chaos. Journal of Economic Behavior and Organization 62, 441-469. 
Zezza, G., 2009. Fiscal policy and the economics of financial balances. European Journal of Economics and Economics Policies: Intervention 6 (2), 289-310. 
Recent UWE Economics Papers

See http://www1.uwe.ac.uk/bl/research/bristoleconomicanalysis for a full list.

1509 Debt cycles, instability and fiscal rules: a Godley-Minsky model

Yannis Dafermos

1508 Evaluating the FLQ and AFLQ formulae for estimating regional input coefficients: empirical evidence for the province of Córdoba, Argentina

Anthony T. Flegg, Leonardo J. Mastronardi and Carlos A. Romero

1507 Effects of preferential trade agreements in the presence of zero trade flows: the cases of China and India

Rahul Sen, Sadhana Srivastava and Don JWebber

1506 Using CHARM to adjust for cross-hauling: the case of the Province of Hubei, China

Anthony T. Flegg, Yongming Huang and Timo Tohmo

1505 University entrepreneurship education experiences: enhancing the entrepreneurial ecosystems in a UK city-region

Fumi Kitagawa, Don J. Webber, Anthony Plumridge and Susan Robertson

1504 Can indeterminacy and self-fulfilling expectations help explain international business cycles?

Stephen McKnight and Laura Povoledo

1503 User-focused threat identification for anonymised microdata

Hans-Peter Hafner, Felix Ritchie and Rainer Lenz

1502 Reflections on the one-minute paper

Damian Whittard

1501 Principles- versus rules-based output statistical disclosure control in remote access environments Felix Ritchie and Mark Elliot

$\underline{2014}$

1413 Addressing the human factor in data access: incentive compatibility, legitimacy and costeffectiveness in public data resources

Felix Ritchie and Richard Welpton

1412 Resistance to change in government: risk, inertia and incentives

Felix Ritchie

1411 Emigration, remittances and corruption experience of those staying behind

Artjoms Ivlevs and Roswitha M. King

1410 Operationalising 'safe statistics': the case of linear regression

Felix Ritchie

1409 Is temporary employment a cause or consequence of poor mental health?

Chris Dawson, Michail Veliziotis, Gail Pacheco and Don J Webber

1408 Regional productivity in a multi-speed Europe

Don J. Webber, Min Hua Jen and Eoin O'Leary 
1407 Assimilation of the migrant work ethic

Chris Dawson, Michail Veliziotis, Benjamin Hopkins

1406 Empirical evidence on the use of the FLQ formula for regionalizing national input-output tables: the case of the Province of Córdoba, Argentina

Anthony T. Flegg, Leonardo J. Mastronardi and Carlos A. Romero

1405 Can the one minute paper breathe life back into the economics lecture?

Damian Whittard

1404 The role of social norms in incentivising energy reduction in organisations

Peter Bradley, Matthew Leach and Shane Fudge

1403 How do knowledge brokers work? The case of WERS

Hilary Drew, Felix Ritchie and Anna King

1402 Happy moves? Assessing the impact of subjective well-being on the emigration decision Artjoms Ivlevs

1401 Communist party membership and bribe paying in transitional economies Timothy Hinks and Artjoms Ivlevs

1315 Global economic crisis and corruption experience: Evidence from transition economies Artjoms Ivlevs and Timothy Hinks

1314 A two-state Markov-switching distinctive conditional variance application for tanker freight returns Wessam Abouarghoub, Iris Biefang-Frisancho Mariscal and Peter Howells

1313 Measuring the level of risk exposure in tanker shipping freight markets Wessam Abouarghoub and Iris Biefang-Frisancho Mariscal

1312 Modelling the sectoral allocation of labour in open economy models Laura Povoledo

1311 The US Fed and the Bank of England: ownership, structure and 'independence' Peter Howells

1310 Cross-hauling and regional input-output tables: the case of the province of Hubei, China Anthony T. Flegg, Yongming Huang and Timo Tohmo

1309 Temporary employment, job satisfaction and subjective well-being Chris Dawson and Michail Veliziotis

1308 Risk taking and monetary policy before the crisis: the case of Germany Iris Biefang-Frisancho Mariscal

1307 What determines students' choices of elective modules?

Mary R Hedges, Gail A Pacheco and Don J Webber

1306 How should economics curricula be evaluated? Andrew Mearman 